\title{
Nonlinear Convection Flow of Micropolar Nanofluid due to a Rotating Disk with Multiple Slip Flow
}

\author{
Chaluma Zemedu and Wubshet Ibrahim (D) \\ Department of Mathematics, Ambo University, Ambo, Ethiopia \\ Correspondence should be addressed to Wubshet Ibrahim; wubshetib@yahoo.com
}

Received 29 February 2020; Revised 20 May 2020; Accepted 28 May 2020; Published 17 June 2020

Academic Editor: Efstratios Tzirtzilakis

Copyright (C) 2020 Chaluma Zemedu and Wubshet Ibrahim. This is an open access article distributed under the Creative Commons Attribution License, which permits unrestricted use, distribution, and reproduction in any medium, provided the original work is properly cited.

\begin{abstract}
In this analysis, steady, laminar, and two-dimensional boundary layer flow of nonlinear convection micropolar nanofluid due to a rotating disk is considered. The mathematical formulation for the flow problem has been made. By means of appropriate similarity transformation and dimensionless variables, the governing nonlinear boundary value problems were reduced into coupled highorder nonlinear ordinary differential equations with numerically solved. The equations were calculated using method bvp4c from matlab software for various quantities of main parameters. The influences of different parameters on skin friction coefficients $f^{\prime \prime}(0)$ and $G^{\prime}(0)$, wall duo stress coefficients $H_{1}^{\prime}(0),-H_{2}^{\prime}(0)$, and $-H_{3}^{\prime}(0)$, the Nusselt number $-\theta^{\prime}(0)$, and Sherwood number $\Omega^{\prime}(0)$, as well as the velocities, temperature, and concentration are analysed and discussed through tables and plotted graphs. The findings indicate that an increase in the values of thermal and solutal nonlinear convection parameters allow to increase the value of velocities $f^{\prime}(\eta)$ and $G(\eta)$ near surface of the disk and reduce at far away from the disk as well as thermal and solutal Grashof numbers tolerate to increase in the value of radial velocity $f^{\prime}(\eta)$ near surface of the disk.
\end{abstract}

\section{Introduction}

Eringen [1] was the first researcher who presents the theory of micropolar fluid for which the classical Navier-Stokes theory is has a limitation for its full description. Consequently, Hamzeh [2] evaluated the behaviour of micropolar Casson fluid on natural convective flow past a solid sphere. It was found that material parameter diminishes the values of the narrow skin friction coefficient, but grows both values of the local Nusselt number and angular velocity profiles as its value rises. Wubshet and Chaluma [3] also reported the variation of density on micropolar nanofluid flow about an isothermal sphere. Moreover, wall shear stress and angular velocity gradient at the wall enhance with an enlargement in the material parameter as illustrated by Mandal and Mukhopadhyay [4]. Furthermore, the flow of MHD and heat transfer due to stretching rotating disk were examined by Mustafa [5] and Akhter et al. [6].

Mostafa and Shimaa [7] reported the influence of magnetic field on flow and heat transfer of a micropolar fluid about a stretching surface in the presence of heat generation (absorption). Also, the effects of microrotation parameter on flow between a rotating and stationary disk was examined by Anwar and Guram [8]. Moreover, Rashidi and Freideonimehr [9] presented the effects of velocity and temperature slip on the entropy generation past rotating disk. Also, the effects of diffusion-thermo and thermodiffusion on radially stretching disk have been evaluated by Khan et al. [10].

The impact of Prandtl number on radiative flow due to stretchable rotating disk with variable thickness was computed by Tasawar et al. [11]. Shamshuddin et al. [12] have evaluated the influence of this parameter on numerical study of heat transfer and viscous flow in a dual rotating extendable disk system employing a non-Fourier heat flux model. They indicated that, with an improvement in the Prandtl number, there is a strong decrease in temperature of fluid as well as radial skin friction. Moreover, the Stefan blowing effect on bioconvective flow and heat transfer of nanofluid over a rotating stretchable disk was reported by Lafiff et al. [13] and Yin et al. [14].

Muhammad and Naeem [15] and Noor et al. [16] have examined the influences of velocity slip with magnetic field 
in micropolar nanofluid flow along rotating disk and in mixed convection lower flow of a micropolar nanofluid along vertically elongating surface accordingly. Also, the flow and heat transfer computations for nanofluid fluid flow and the impact of heat generation/consumption and thermal radiation over a rotating disk were analysed by Narfifah et al. [17], Mushtaq and Mustafa [18], and Anwer et al. [19]. Moreover, Tasawar et al. [20] had discussed the impact of thermal slip condition on MHD flow of $\mathrm{Cu}$-water nanofluid due to a rotating disk. They found that thermal boundary thickness increased for lower thermal slip parameter values, but increasing the values of it reduced heat transfer from the disk to the adjacent fluid. Moreover, the numerical study of nanofluid flow and heat transfer over a rotating disk was examined by Ahmad et al. [21]. MHD mixed convection movement of a nanofluid over nonlinear enlarging sheet including variable Brownian and thermophoretic diffusion coefficient have been evaluated by Sumalatha and Shanker [22], and the results illustrated that the influence of nonlinear stretching parameter drops both the flow of the fluid as well as temperature distribution.

All the above research articles have been on the flow over a plane, over a stretching surface, on MHD boundary flow, or in many other areas. In this paper, we evaluate numerically the nonlinear convection flow of micropolar nanofluid due to a rotating disk in the presence of multiple slip conditions, using bvp4c from matlab. The outcomes of physical parameters on fluid velocity, temperature, and concentration were discussed and indicated in graphs and tables as well.

\section{Mathematical Formulation}

Let us choose the cylindrical system $(r, \omega, z)$ in the direction component of the flow velocity $(u, v, w)$ and the angular velocity components $(H 1, H 2, H 3)$ correspondingly. The study considers incompressible, laminar, and nonlinear convection flow of micropolar nanofluid over a circular disk at $z=0$. The disk rotates with uniform microrotation $r M_{0}$ about the $z$-axis. As the result of revolving symmetry the end products in the azimuthal direction may be considered. The wall of the gyrating disk has constant temperature $T_{w}$ and concentration $C_{w}$ despite the fact the ambient temperature and concentration are represented by $T_{\infty}$ and $C_{\infty}$ correspondingly, as shown in Figure 1. By means of Mandal and Mukhopadhyay [4], Anwer and Guram [8], Tasawar et al. [11], Noor et al. [16], and Sajjad et al. [23] the governing differential equations of the flow are given as follows:

$$
\begin{aligned}
& \frac{\partial(u)}{\partial r}+\frac{\partial(w)}{\partial z}+\frac{u}{r}=0 \\
& u \frac{\partial u}{\partial r}+w \frac{\partial u}{\partial z}-\frac{v^{2}}{r}=\left(\frac{\mu+\kappa}{\rho}\right)\left(\frac{\partial^{2} u}{\partial r^{2}}+\frac{1}{r} \frac{\partial u}{\partial r}-\frac{u}{r^{2}}+\frac{\partial^{2} u}{\partial z^{2}}\right)-\frac{\kappa}{\rho} \frac{\partial N_{2}}{\partial z}+g\left(\sigma\left(T-T_{\infty}\right)+\sigma_{t}\left(T-T_{\infty}\right)^{2}\right) \\
& +g\left(\sigma\left(C-C_{\infty}\right)+\sigma_{s}\left(C-C_{\infty}\right)^{2}\right) \sin (\omega), \\
& u \frac{\partial v}{\partial r}+w \frac{\partial v}{\partial z}+\frac{u v}{r}=\left(\frac{\mu+\kappa}{\rho}\right)\left(\frac{\partial^{2} v}{\partial r^{2}}+\frac{1}{r} \frac{\partial v}{\partial r}-\frac{v}{r^{2}}+\frac{\partial^{2} v}{\partial z^{2}}\right)+\frac{\kappa}{\rho}\left(\frac{\partial N_{1}}{\partial z}-\frac{\partial N_{3}}{\partial r}\right)+g\left(\sigma\left(T-T_{\infty}\right)+\sigma_{t}\left(T-T_{\infty}\right)^{2}\right) \\
& +g\left(\sigma\left(C-C_{\infty}\right)+\sigma_{s}\left(C-C_{\infty}\right)^{2}\right) \sin (\omega), \\
& u \frac{\partial w}{\partial r}+w \frac{\partial w}{\partial z}=\left(\frac{\mu+\kappa}{\rho}\right)\left(\frac{\partial^{2} w}{\partial r^{2}}+\frac{1}{r} \frac{\partial w}{\partial r}+\frac{\partial^{2} w}{\partial z^{2}}\right)+\frac{\kappa}{\rho} \frac{N_{2}}{r} \\
& u \frac{\partial N_{1}}{\partial r}+w \frac{\partial N_{1}}{\partial z}-v \frac{N_{2}}{r}=\frac{(a+b+c)}{\rho j} \frac{\partial}{\partial r}\left(\frac{\partial N_{1}}{\partial r}+\frac{N_{1}}{r}+\frac{\partial N_{3}}{\partial z}\right)-\frac{c}{\rho j} \frac{\partial}{\partial z}\left(\frac{\partial N_{3}}{\partial r}-\frac{\partial N_{1}}{\partial z}\right)-\frac{\kappa}{\rho j} \frac{\partial v}{\partial z}-2 \frac{\kappa}{\rho j} N_{1}, \\
& u \frac{\partial N_{2}}{\partial r}+w \frac{\partial N_{2}}{\partial z}+v \frac{N_{1}}{r}=\frac{c}{\rho j}\left[\frac{\partial}{\partial r}\left(\frac{\partial N_{2}}{\partial r}+\frac{N_{2}}{r}\right)+\frac{\partial^{2} N_{2}}{\partial z^{2}}\right]+\frac{\kappa}{\rho j} \frac{\partial u}{\partial z}-\frac{2 \kappa N_{2}}{\rho j}, \\
& u \frac{\partial N_{3}}{\partial r}+w \frac{\partial N_{3}}{\partial z}=\frac{(a+b+c)}{\rho j} \frac{\partial}{\partial z}\left(\frac{\partial N_{1}}{\partial r}+\frac{N_{1}}{r}+\frac{\partial H_{3}}{\partial z}\right)-\frac{c}{\rho j} \frac{\partial}{\partial r}\left[r\left(\frac{\partial N_{1}}{\partial z}-\frac{\partial N_{3}}{\partial r}\right)\right]+\frac{\kappa}{\rho j}(2 v)-2 \frac{\kappa N_{3}}{\rho j} \\
& u \frac{\partial T}{\partial r}+w \frac{\partial T}{\partial z}=\frac{K}{\rho c_{p}}\left(\frac{\partial^{2} T}{\partial r^{2}}+\frac{1}{r} \frac{\partial T}{\partial r}+\frac{\partial^{2} T}{\partial z^{2}}\right)+\gamma D_{B}\left(\frac{\partial C \partial T}{\partial r \partial r}+\frac{\partial C \partial T}{\partial z \partial z}\right)+\gamma \frac{D_{T}}{T_{\infty}}\left(\left(\frac{\partial T}{\partial r}\right)^{2}+\left(\frac{\partial T}{\partial z}\right)^{2}\right) \\
& u \frac{\partial C}{\partial r}+w \frac{\partial C}{\partial z}=D_{B}\left(\frac{\partial^{2} C}{\partial r^{2}}+\frac{1}{r} \frac{\partial C}{\partial r}+\frac{\partial^{2} C}{\partial z^{2}}\right)+\frac{D_{T}}{T_{\infty}}\left(\frac{\partial^{2} T}{\partial r^{2}}+\frac{1}{r} \frac{\partial T}{\partial r}+\frac{\partial^{2} T}{\partial z^{2}}\right)
\end{aligned}
$$




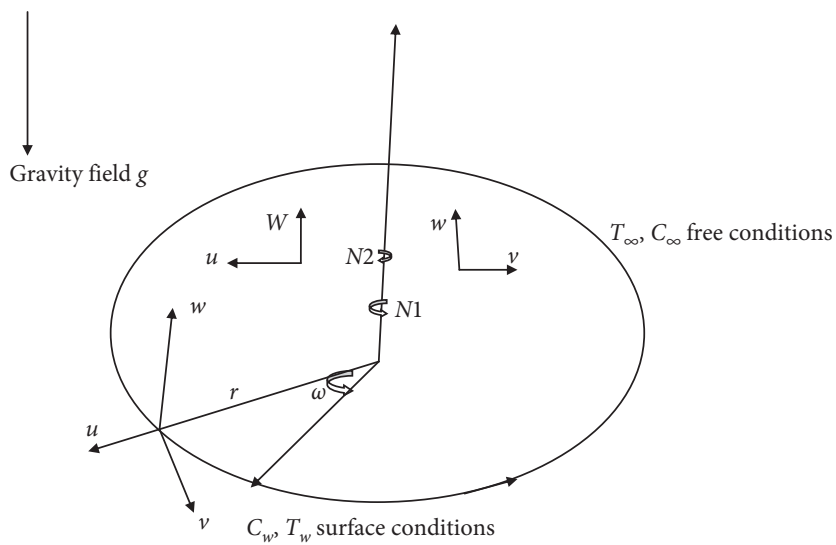

Figure 1: Physical model and coordinate system.

with boundary conditions

$$
\begin{aligned}
& u=L \frac{\partial u}{\partial z} \\
& u=L \frac{\partial u}{\partial r} \\
& v=r M_{0}+L \frac{\partial v}{\partial z}, \\
& v=L \frac{\partial v}{\partial r} \\
& w=0, \\
& N_{1}=n \frac{\partial N_{1}}{\partial z}, \\
& N_{1}=n \frac{\partial N_{1}}{\partial r}, \\
& N_{2}=n \frac{\partial N_{2}}{\partial z}, \\
& N_{2}=n \frac{\partial N_{2}}{\partial r}, \\
& N_{3}=r M_{0} \text {, } \\
& T=T_{w}+h \frac{\partial T}{\partial z}, \\
& T=T_{w}+h \frac{\partial T}{\partial r}, \\
& C=C_{w}+m \frac{\partial C}{\partial z} \\
& C=C_{w}+m \frac{\partial C}{\partial r}, \\
& \text { at } z=0 \text {, }
\end{aligned}
$$

$$
\begin{aligned}
u & \longrightarrow u_{\infty}, \\
v & \longrightarrow v_{\infty}, \\
N & \longrightarrow 0, \\
T & \longrightarrow T_{\infty}, \\
C & \longrightarrow C_{\infty}, \\
\text { as } z & \longrightarrow \infty,
\end{aligned}
$$

where $\left(N_{1}, N_{2}, N_{3}\right)$ are angular velocity in the $r, \omega$, and $z$ axes, correspondingly, $(\kappa, a, b, c)$ are material constants (viscosity coefficients), $L$ stands for momentum slip factor, $n$ stands for angular slip factor, $h$ represents thermal factor, $m$ is solutal jump factor, $\mu$ stands for the coefficient of fluid viscosity, $\rho$ is the density, $c_{p}$ stands for the specific heat, $g$ represents the gravity, $j=\left(\chi / M_{0}\right)$ is the microinertia per unit mass, $\kappa$ is the vortex viscosity, Tstands for temperature, $K$ is the thermal conductivity of the fluid, $T_{w}=\left(T_{\infty}+\Delta T\right)$ and $C_{w}=\left(C_{\infty}+\Delta C\right)$ represent the variable temperature and concentration at the surface, where $\Delta T$ and $\Delta C$ being constants give the rate of growth of temperature and concentration alongside the surface and $T_{\infty}$ and $C_{\infty}$ stand for the uniform temperature, concentration of the free $\operatorname{stream}(\nabla \rho / \rho)=\left(\sigma\left(T-T_{\infty}\right)+\sigma_{t}\left(T-T_{\infty}\right)^{2}+\sigma^{*}\left(C-C_{\infty}\right)+\right.$ $\left.\sigma_{s}\left(C-C_{\infty}\right)^{2}\right)$, and $\sigma$ and $\sigma^{*}$ are constants, $\sigma_{t}$ and $\sigma_{s}$ are the constant coefficients of thermal and volumetric expansion, respectively. This relation will be nonlinear density, temperature, and concentration (NDTC) variation. $\mathrm{Y}=\left((\rho c)_{p} /(\rho c)_{f}\right)$ is the ratio between the effective heat capability of the nanoparticle material and the heat capability of the fluid and $D_{B}$ and $D_{T}$ stand for the Brownian and the thermophoretic diffusion coefficient, respectively. Let $r(x)=d \sin (x / d)$ be the radial distance from the symmetrical axis to the surface.

By using the nondimensional variables such as $\omega=(x / d), \quad \eta=z \sqrt{2 M_{0} / \chi}, \quad r=(r(\omega) / d), \quad u=r M_{0} f^{\prime}(r, \eta)$, $v=r M_{0} G(r, \eta), \quad w=-\sqrt{2 M_{0} \chi} f(r, \eta), \quad \chi=((\mu+\kappa) / \rho)$, $N_{1}=r M_{0} \sqrt{2 M_{0} / \chi} H_{1}(r, \eta), N_{2}=r M_{0} \sqrt{2 M_{0} / \chi} H_{2}(r, \eta)$, 


$$
\begin{aligned}
N_{3} & =r M_{0} H_{3}(r, \eta), \\
\theta(r, \eta) & =\frac{T-T_{\infty}}{T_{w}-T_{\infty}}, \\
\Omega(r, \eta) & =\frac{C-C_{\infty}}{C_{w}-C_{\infty}} .
\end{aligned}
$$

The continuity equation can be integrated so that it satisfies equation (1). Hence, equations (2)-(9) can be written in the following nonlinear system of ODEs:

$$
\begin{gathered}
2 f^{\prime \prime \prime}+B 1\left(0.5 H_{2} f-2 H_{2}^{\prime}\right)+0.5 f^{2}\left(\tan (\omega) \frac{\partial f}{\partial \omega}-2 f^{\prime}\right) \\
-\tan (\omega) f^{\prime} \frac{\partial f^{\prime}}{\partial \omega}+G^{2}-\left(f^{\prime}\right)^{2} \\
+\sin (\omega)\left(\frac{G r}{\operatorname{Re}^{2}}\left(\theta+\lambda \theta^{2}\right)+\frac{G m}{\operatorname{Re}^{2}} G m(\Omega+s \Omega)^{2}\right)=0, \\
2 G^{\prime \prime}+B_{1} H_{1}^{\prime}+G^{\prime} f-2 f^{\prime} G-\tan (\omega) f \frac{\partial G}{\partial \omega}+\sin (\omega) \\
\left(\frac{G r}{\operatorname{Re}^{2}} G r\left(\theta+\lambda \theta^{2}\right)+\frac{G m}{\operatorname{Re}^{2}} G m\left(\Omega+s \Omega^{2}\right)\right)=0, \\
H_{1}^{\prime \prime}-0.5 B_{2}\left(G^{\prime}+2 H_{1}\right)-0.5 B_{3}\left(f^{\prime} H_{1}+\tan (\omega) \frac{\partial H_{1}}{\partial \omega} f^{\prime}\right. \\
\left.-2 f H_{1}^{\prime}-G H_{2}\right)=0, \\
-\theta_{3}^{\prime \prime}+N b \Omega^{\prime} \theta^{\prime}+2 N t\left(\theta^{\prime}\right)^{2}+2 \theta^{\prime} f-\tan (\omega) f^{\prime} \frac{\partial \theta}{\partial \omega}=0, \\
2 H_{2}^{\prime \prime}+B_{2}\left(f^{\prime \prime}-2 H_{2}\right)-B_{3}\left(f^{\prime} H_{2}+\tan (\omega) \frac{\partial H_{2}}{\partial \omega} f^{\prime}\right. \\
\left.\left.-H_{2} f\right)+G H_{1}\right)=0,
\end{gathered}
$$

with the boundary conditions.
At

$$
\begin{aligned}
& \eta=0: f(0) \\
& f^{\prime}(0)=s_{0} f^{\prime \prime}(0), \\
& \frac{\partial f^{\prime}(0)}{\partial \omega}=\frac{(2 \mathrm{Re})^{1 / 2}}{\sin (\omega)} f^{\prime \prime}(0), \\
& \frac{\partial f(0)}{\partial r}=0, \\
& G(0)=1+s_{0} G^{\prime}(0), \\
& \frac{\partial G(0)}{\partial \omega}=\frac{(2 \mathrm{Re})^{1 / 2}}{\sin (\omega)} G^{\prime}(0), \\
& H_{1}(0)=s_{1} H_{1}^{\prime}(0), \\
& \frac{\partial H_{1}(0)}{\partial \omega}=\frac{(2 \mathrm{Re})^{1 / 2}}{\sin (\omega)} H_{1}^{\prime}(0), \\
& H_{2}(0)=s_{1} H_{2}^{\prime}(0) \text {, } \\
& \frac{\partial H_{2}(0)}{\partial \omega}=\frac{(2 \mathrm{Re})^{1 / 2}}{\sin (\omega)} H_{2}^{\prime}(0) \text {, } \\
& H_{3}(0)=1 \text {, } \\
& \frac{\partial H_{3}(0)}{\partial r}=0, \\
& \theta(0)=1+s_{2} \theta^{\prime}(0), \\
& \frac{\partial \theta(0)}{\partial \omega}=\frac{(2 \mathrm{Re})^{1 / 2}}{\sin (\omega)} \theta^{\prime}(0), \\
& \Omega(0)=1+s_{3} \Omega^{\prime}(0), \\
& \frac{\partial \Omega(0)}{\partial \omega}=\frac{(2 \mathrm{Re})^{1 / 2}}{\sin (\omega)} \Omega^{\prime}(0), \\
& \text { as } \eta \longrightarrow \infty: f^{\prime}=G \\
& \theta=0 \text {, } \\
& H_{1}=H_{2} \\
& \Omega=0 \text {, }
\end{aligned}
$$

where prime represents differential with respect to $\eta, s_{0}=$ $L \sqrt{2 M_{0} / \chi}$ is the velocity slip parameter, $s_{1}=n \sqrt{2 M_{0} / \chi}$ denotes microrotation slip parameter, $s_{2}=h \sqrt{2 M_{0} / \chi}$ stands for thermal parameter, $s_{3}=m \sqrt{2 M_{0} / \chi}$ withstands for solutal parameter, $\left(B_{1}=(\kappa /(\mu+\kappa)), B_{2}=\left(\kappa \chi / c M_{0}\right), B_{3}=(\chi \rho j / c)\right.$, 
$B_{4}=((a+b) /(a+b+c)), \quad B_{5}=\left(\kappa \chi / M_{0}(a+b+c)\right), \quad$ and $B_{6}=(\rho j \chi /(a+b+c))$ are angular velocity parameters, $\left(\mathrm{Gr} / \mathrm{Re}^{2}\right)$ and $\left(\mathrm{Gm} / \mathrm{Re}^{2}\right)$ denote thermal and solutal mixed convection parameters (or Archimedes numbers), $G r=\left(r^{3} g \sigma\left(T_{w}-T_{\infty}\right) / \chi^{2}\right)$ represents thermal Grashof number, $G m=\left(r^{3} g \sigma^{*}\left(C_{w}-C_{\infty}\right) / \chi^{2}\right)$ represents solutal Grashof number, $\operatorname{Re}=\left(M_{0} r^{2} / \chi\right)$ is Reynolds number, and $\lambda=\left(\sigma_{t} / \sigma\right)\left(T_{w}-T_{\infty}\right)$ and $s=\left(\sigma_{s} / \sigma^{*}\right)\left(C_{w}-C_{\infty}\right)$ are thermal and solutal nonlinear convection parameters, correspondingly. We observe that, for $\lambda=s=0$, the flow of equations (14) and (15) become mixed convective micropolar nanofluid. Also, the relation of buoyancy forces ( $G r: \mathrm{Re}^{2}$ and $G m: \mathrm{Re}^{2}$ ) seen in the these equations are the dimensionless parameters, indicating the ratios between the buoyancy forces caused by temperature, concentration change, and the ratio inertial to viscous forces owing to kinematic viscosity change. Furthermore, $G r$ and $G m$ are zero for nonbuoyancy influence because of thermal and mass diffusions, as $\mathrm{Re} \longrightarrow \infty$, i.e., $\left(\mathrm{Gr} / \mathrm{Re}^{2}\right)$ and $\left(\mathrm{Gm} / \mathrm{Re}^{2}\right) \approx 0$ are for nonbuoyancy effect owing to momentum diffusion and when $\left(G r / \operatorname{Re}^{2}\right)=\left(G m / \operatorname{Re}^{2}\right)=1$ are for thermal, mass buoyancy forces, and inertial to viscous forces of the same strength. $\operatorname{Pr}=\left(\rho \chi c_{p} / K\right)$ is Prandtl number, $S c=\operatorname{Pr} L e=\left(\chi / D_{B}\right)$ is Schmidt number, $N b=\left((\rho c)_{p} /(\rho c)_{f}\right)\left(D_{B} / \chi\right)\left(C_{w}-C_{\infty}\right)$ stands for Brownian motion parameter, and $N t=\left((\rho c)_{p} /(\rho c)_{f}\right)$ $\left(D_{T} / T_{\infty} \chi\right)\left(T_{w}-T_{\infty}\right) \quad$ represents thermophoresis parameter.

It can appear that, due to the rotational symmetry, the derivative in the radial direction may be neglected and equations (14)-(21) are reduced to the next nonlinear system of ordinary differential equations:

$$
\begin{array}{r}
2 f^{\prime \prime \prime}+B 1\left(0.5 H_{2} f-2 H_{2}^{\prime}\right)-f^{2} f^{\prime}+G^{2}-\left(f^{\prime}\right)^{2}=0, \\
2 G^{\prime \prime}+B_{1} H_{1}^{\prime}+G^{\prime} f-2 f^{\prime} G=0, \\
H_{1}^{\prime \prime}-0.5 B_{2}\left(G^{\prime}+2 H_{1}\right)-0.5 B_{3}\left(f^{\prime} H_{1}-2 f H_{1}^{\prime}-G H_{2}\right)=0, \\
\left.2 H_{2}^{\prime \prime}+B_{2}\left(f^{\prime \prime}-2 H_{2}\right)-B_{3}\left(f^{\prime} H_{2}-H_{2} f\right)+G H_{1}\right)=0, \\
\left.2 H_{3}^{\prime \prime}+4 B_{4} H_{1}^{\prime}+2 B_{5}\left(G-2 H_{3}\right)-B_{6}\left(-f H_{3}\right)+2 f H_{3}^{\prime}\right)=0, \\
\frac{2}{\operatorname{Pr}} \theta^{\prime \prime}+N b \Omega^{\prime} \theta^{\prime}+2 N t\left(\theta^{\prime}\right)^{2}+2 \theta^{\prime} f=0, \\
\Omega^{\prime \prime}-0.5 \operatorname{Pr} \frac{N t}{N b}\left(N b \Omega^{\prime} \theta^{\prime}+2 N t\left(\theta^{\prime}\right)^{2}+\theta^{\prime} f\right)+\operatorname{Pr} L e f \Omega^{\prime}=0,
\end{array}
$$


with the boundary conditions.

At

$$
\begin{aligned}
\eta & =0: \\
f(0) & =0, f^{\prime}(0)=s_{0} f^{\prime \prime}(0), \\
\frac{\partial f^{\prime}(0)}{\partial \omega} & =\frac{\partial f(0)}{\partial r} \\
G(0) & =1+s_{0} G^{\prime}(0), \\
\frac{\partial G(0)}{\partial \omega} & =0 \\
\frac{\partial s}{H_{1}(0)} & =s_{1} H_{1}^{\prime}(0), \\
\frac{\partial H_{1}(0)}{\partial \omega} & =0, \\
\frac{\partial H_{3}(0)}{\partial r} & =0, \\
\frac{\partial \theta(0)}{\partial \omega} & =0, \\
\frac{\partial H_{2}(0)}{\partial \omega} & =0 \\
H_{3}(0) & =1, \\
& =s_{1} H_{2}^{\prime}(0),
\end{aligned}
$$

The physical measures of awareness in this problem are the narrow skin friction coefficients $C_{f r, \omega}$, surface couple stresses $m_{w r, \omega}$, the Nusselt number $\mathrm{Nu}$, and the Sherwood Sh number, and they can be written as follows:

$$
\begin{aligned}
C_{f r} & =\frac{\tau_{z r}}{\rho\left(r M_{0}\right)^{2}}, \\
C_{f \omega} & =\frac{\tau_{z \omega}}{\rho\left(r M_{0}\right)^{2}}, \\
M_{r} & =\frac{m_{w r}}{\rho M_{0} \chi j(r)^{2}}, \\
M_{\omega} & =\frac{m_{w \omega}}{\rho M_{0} \chi j(r)^{2}}, \\
M r & =\frac{m_{r}}{\rho M_{0} \chi j r}, \\
\mathrm{Nu} & =r \frac{q_{w}}{\kappa\left(T_{w}-T_{\infty}\right)}, \\
\mathrm{Sh} & =r \frac{q_{m}}{D_{B}\left(C_{w}-C_{\infty}\right)},
\end{aligned}
$$

where $\tau_{z r}=(\mu+\kappa)((\partial u / \partial z)+(\partial w / \partial r)), \quad \tau_{z \omega}=(\mu+\kappa)((\partial v /$ $\partial z)+(\partial w / \partial r)), q_{w}=-K(\partial T / \partial z)_{(z=0)}, q_{m}=D_{B}(\partial C / \partial z)_{(z=0)}$, $M_{r}=-(a+b+c)\left(\partial N_{2} / \partial z\right), \quad M_{\omega}=c\left(\partial N_{1} / \partial z\right), \quad$ and $m r=$ $(a+b+c)\left(\partial N_{3} / \partial z\right)$. Using the dimensionless variables (12) and the boundary conditions (20), the narrow skin friction coefficients surface couple stresses, the Nusselt number and the Sherwood number are obtained:

$$
\begin{aligned}
f^{\prime \prime}(0) & =C_{f r} \sqrt{\frac{R e}{2}}, \\
G^{\prime}(0) & =C_{f \omega} \sqrt{\frac{R e}{2}}, \\
H_{1}^{\prime}(0) & =\frac{B_{3}}{2 R e} m_{\omega}, \\
-H_{2}^{\prime}(0) & =\frac{B_{6}}{2 R e} m_{r}, \\
-H_{3}^{\prime}(0) & =B_{6} M r \sqrt{\frac{\chi}{2 M_{0}}}, \\
\mathrm{Nu} \frac{1}{\sqrt{2 R e}} & =-\theta^{\prime}(0), \\
\operatorname{Sh} \frac{1}{\sqrt{2 R e}} & =\Omega^{\prime}(0) .
\end{aligned}
$$

\section{Numerical Solution}

Pairs of seven harmonized high order ordinary differential equations (14)-(20), subjected to the boundary conditions, equation (21), are answered numerically using the function bvp4c from matlab software for various values of physical parameters and numbers.

Statistical results are found using Matlab BVP solver bvp4c from matlab which is a finite difference code that realize the three-stage Lobatto IIIa formulation. To apply bvp4c from matlab, first, equations (14)-(20) are converted into a system of first-order equations. 
Second, assemble a boundary value problem (bvp) and using the bvp solver in matlab to numerically solve this system, including the above boundary condition and income on a suitable finite value for the far field boundary condition, that is, $\eta \longrightarrow \infty$, say $\eta_{\infty}=1$ and the step size is taken as $\Delta \eta=0.01$, the numerical result is obtained; it is exact to the fifth decimal place as the measure of convergence. In solving the BVP by means of matlab, bvp4c has only two point of views: a function ODEs for calculation of the residual in the boundary conditions and a building solint that provides a guess for a mesh. The ODEs are handled exactly as in the
Matlab IVP solvers. Further clarification on the procedure of bvp4c is found in the book by Shampine et al. [24].

Let $\quad y(1)=f, \quad y(2)=f^{\prime}, \quad y(3)=f^{\prime \prime}, \quad y(4)=G$, $y(5)=G^{\prime}, y(6)=H_{1}, y(7)=H_{1}^{\prime}, y(8)=H_{2}, y(9)=H_{2}^{\prime}$, $y(10)=H_{3}, y(11)=H_{3}^{\prime}, y(12)=\theta, y(13)=\theta^{\prime}, y(14)=\Omega$, $y(15)=\Omega^{\prime}, y(16)=(\partial f / \partial \omega), y(17)=\left(\partial f^{\prime} / \partial \omega\right), y(18)=$ $(\partial G / \partial \omega), y(19)=\left(\partial H_{1} / \partial \omega\right), y(20)=\left(\partial H_{2} / \partial \omega\right), y(21)=$ $\left(\partial H_{3} / \partial \omega\right), y(22)=(\partial \theta / \partial \omega), y(23)=(\partial \Omega / \partial \omega)$, and $y=[f$, $f^{\prime}, f^{\prime \prime}, G, G^{\prime}, H_{1}, H_{1}^{\prime}, H_{2}, H_{2}^{\prime}, H_{3}, H_{3}^{\prime}, \theta, \theta^{\prime}, \Omega, \Omega^{\prime},(\partial f / \partial \omega)$, $\left(\partial f^{\prime} / \partial \omega\right), \quad(\partial G / \partial \omega), \quad\left(\partial H_{1} / \partial \omega\right), \quad\left(\partial H_{2} / \partial \omega\right), \quad\left(\partial H_{3} / \partial \omega\right)$, $(\partial \theta / \partial \omega),(\partial \Omega / \partial \omega)]^{T}$ give

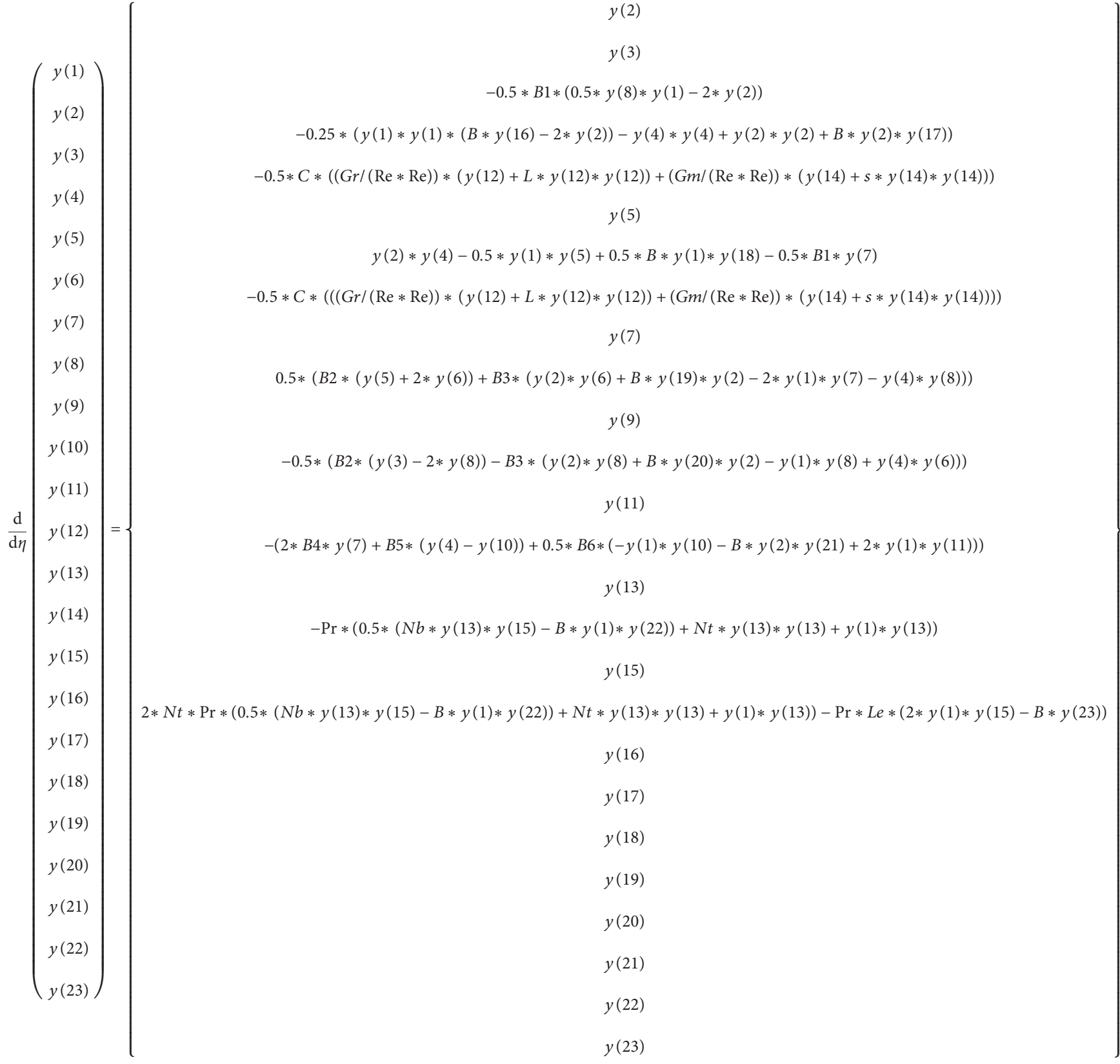




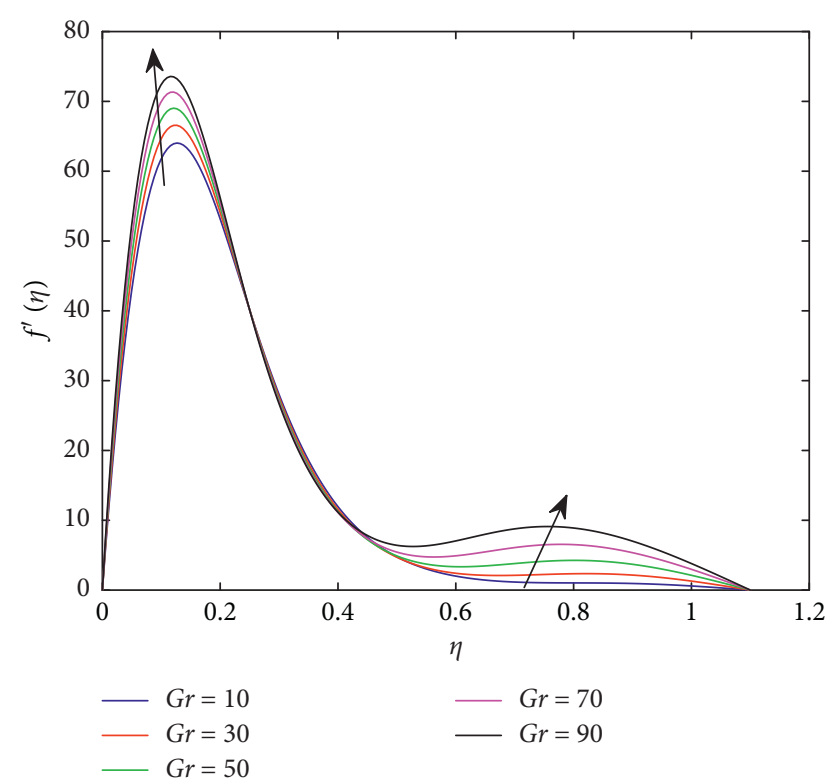

FIGURE 2: Graph $f^{\prime}$ profile for different values of $G r$ when $G m=$ $100, B 1=5, B 2=B 5=s 2=0.2, s=0, \quad B 6=0.3, B 3=B 4=s 1=$ $N b=0.1, \quad L e==N t=\lambda=0.5, s=1, R e=0.01, \operatorname{Pr}=0.72, \quad$ and $\omega=1$.

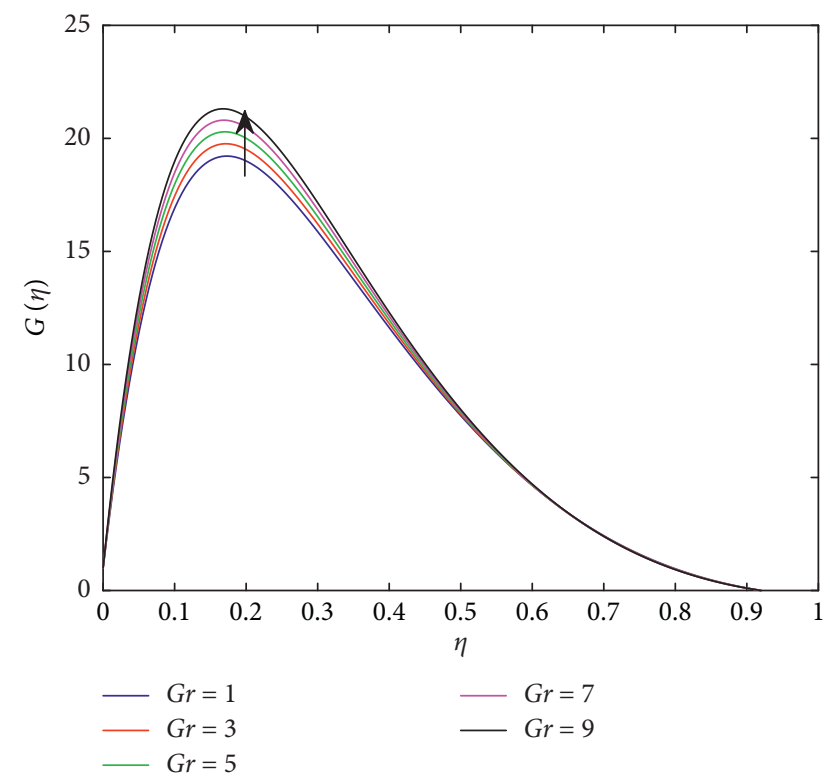

Figure 3: Graph $G(\eta)$ for different values of Gr when $G m=20$.

\section{Results and Discussion}

In this section, the results of different governing physical parameters on nondimensional velocity, temperature, concentration, skin friction and wall couple stress coefficients and confined Nusselt and Sherwood numbers have been discussed. In this study, the comparison with the literature value is not compared, since there is no related article.

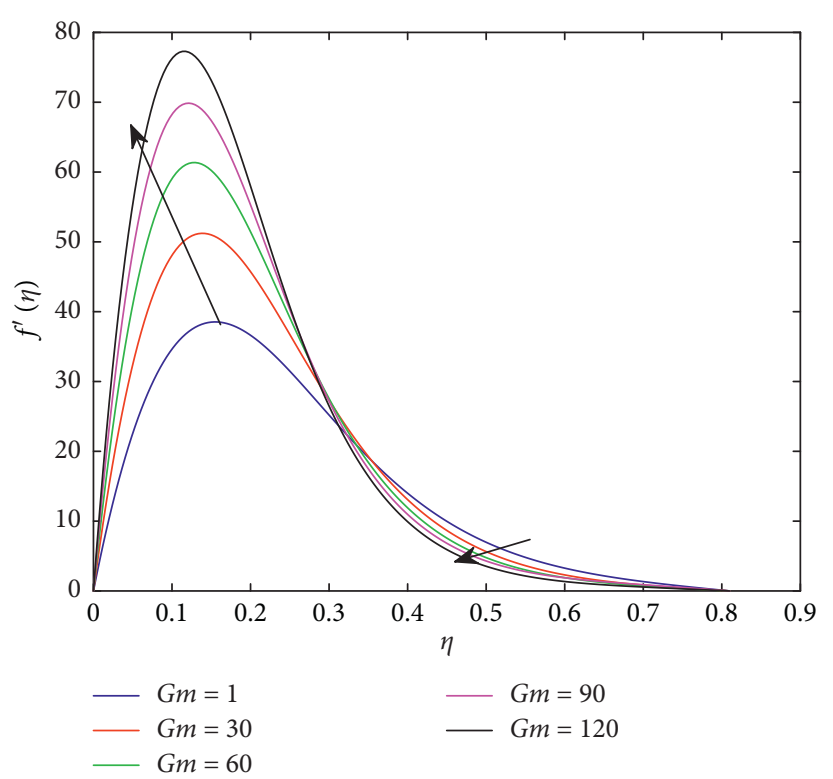

Figure 4: Graph $f^{\prime}(\eta)$ profile for different values of $\mathrm{Gm}$ when $G r=70$.

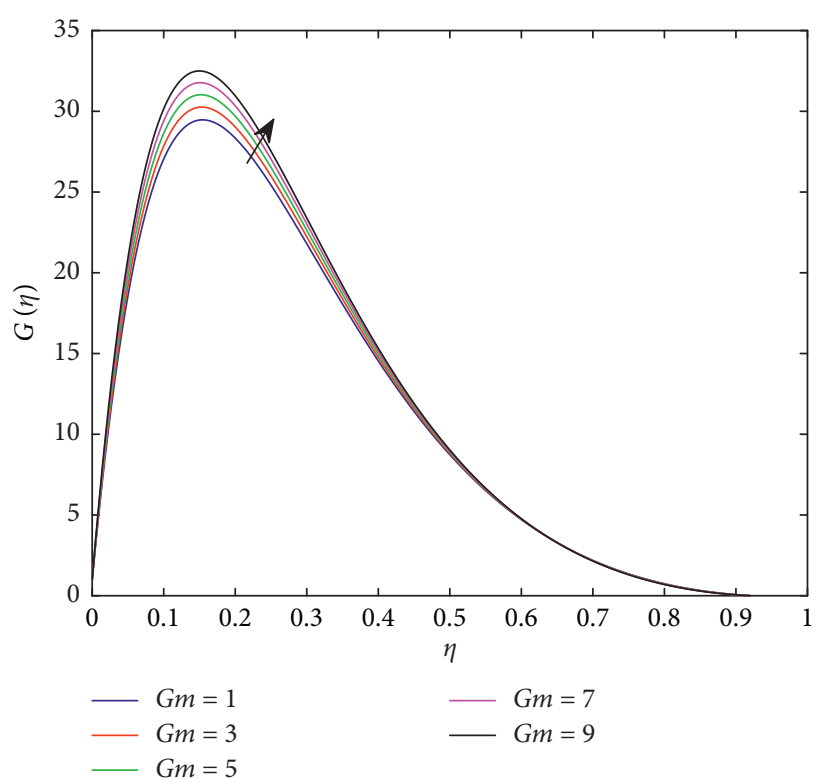

Figure 5: Graph $G(\eta)$ for different values of $\mathrm{Gm}$ when $B 1=2$.

4.1. Velocity Profiles. The dimensionless velocity profile graphs of $f^{\prime}(\eta), G(\eta)$ for different values of angular velocity parameter $B_{1}$, thermal and solutal nonlinear convection parameters $(\lambda, s)$, and thermal and solutal Grashof numbers $(G r, G m)$ are shown in Figures 2-11. Figures 2-9 reveal that an increase in values of $G r, G m, \lambda$, and $s$ reduces the kinematic viscosity of the fluid flow which falls opposite to the flow of the fluid that results in an increase of the magnitude of radial and azimuthal velocity profiles $f^{\prime}(\eta)$ and $G(\eta)$ near the surface of the disk, but they decrease with an enhancement of $G m, \lambda$, and $s$ far away from the surface. 


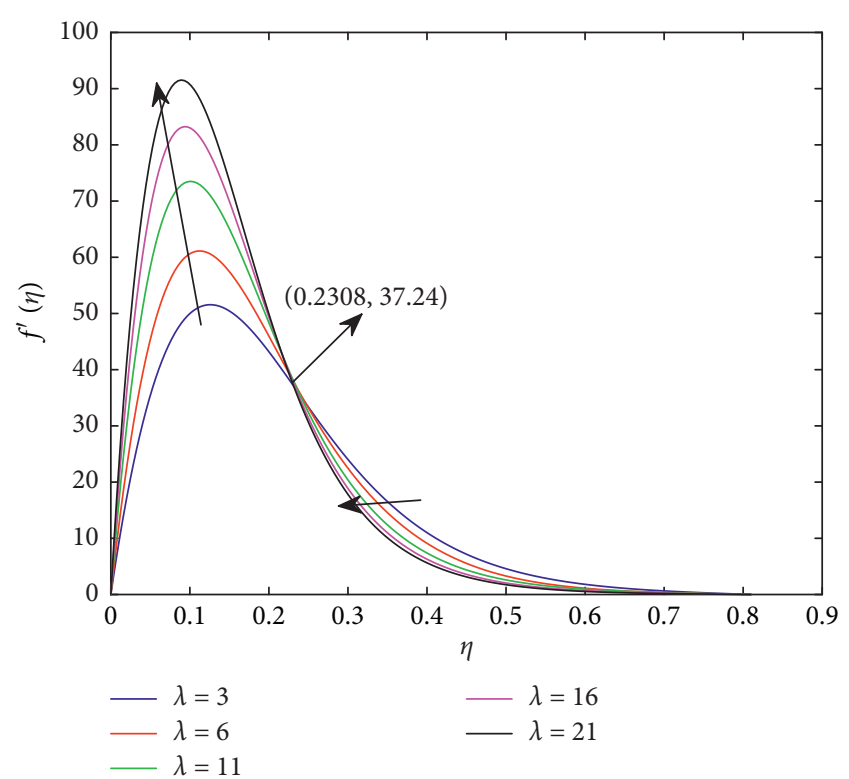

Figure 6: Graph $f^{\prime}$ profile for different values of $\lambda$ when $s=0.1$.

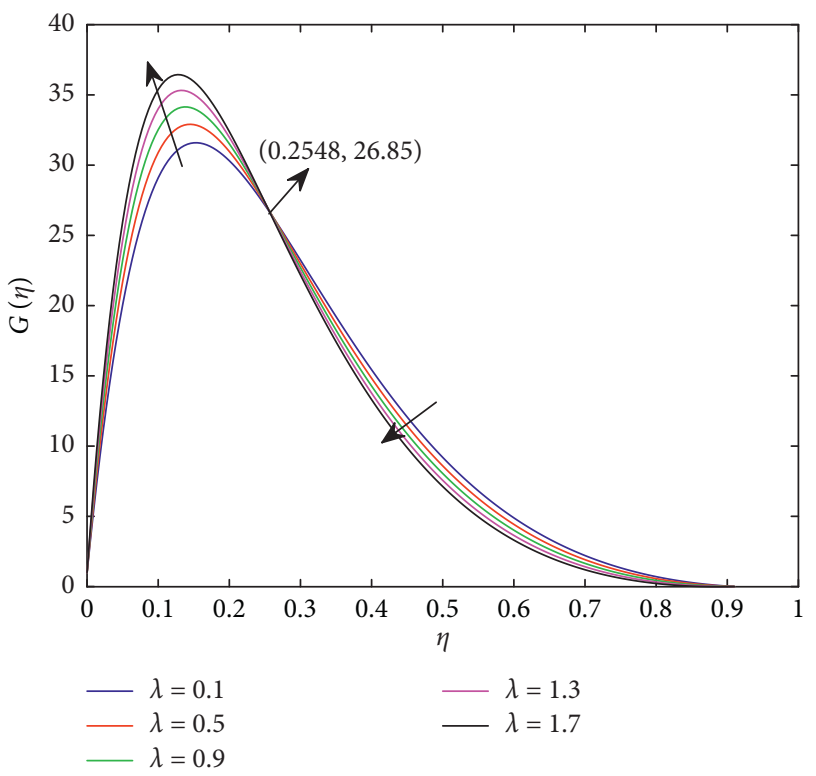

Figure 7: Graph $G(\eta)$ for different values of $\lambda$.

Moreover, boost in the values of angular velocity parameter $B 1$ raises the vortex viscosity of the fluid flow which adds opposition to flow of the fluid that results in declination of the fluid velocity profile $f^{\prime}(\eta)$, but the reverse effects are observed on the fluid velocity profile $G(\eta)$ as seen in Figures 10 and 11 .

4.2. Temperature and Concentration Profiles. The influences of thermal and solutal jump parameters $s 2$ and $s 3$, nonlinear convection parameters $(\lambda, s)$, and thermal and solutal Grashof numbers $(G r, G m)$ on temperature and

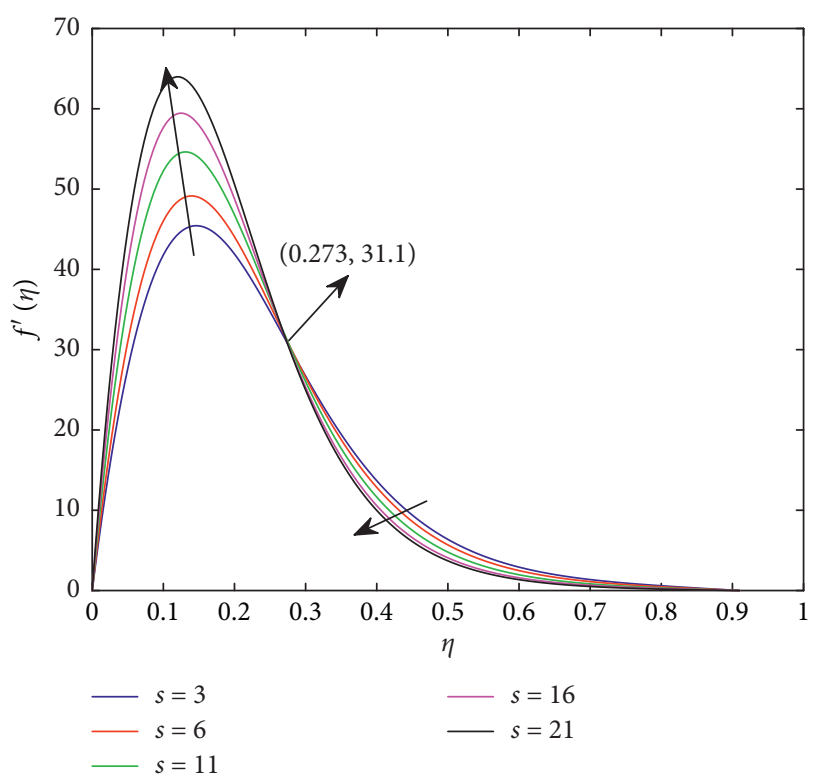

Figure 8: Graph $f^{\prime}$ profile for different values of $s$ when $G m=9, G r=80$, and $\lambda=0.1$.

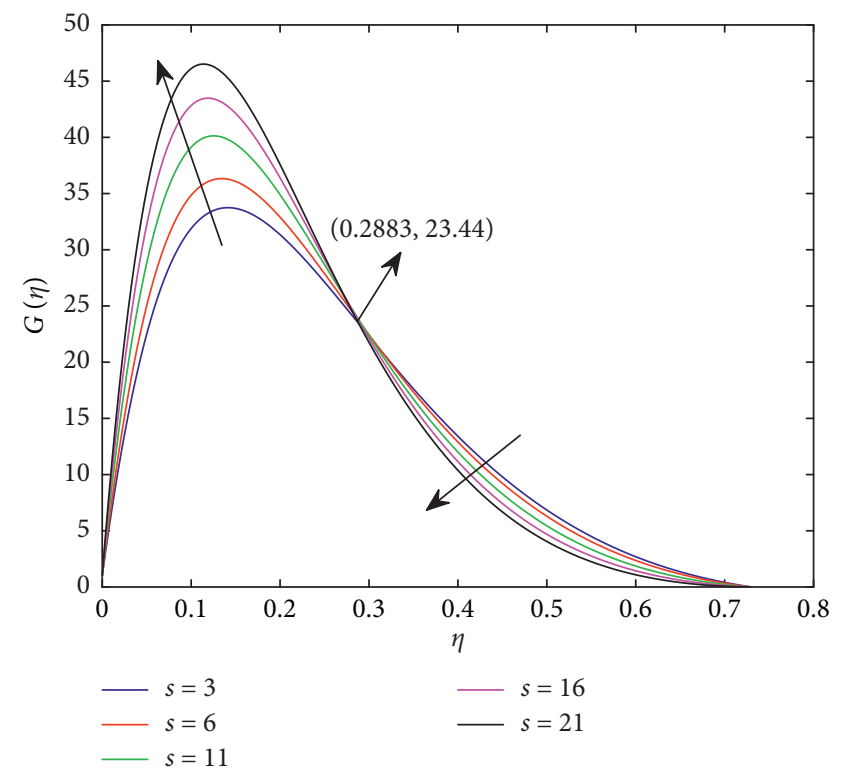

Figure 9: Graph $G(\eta)$ for different values of $s$ when $G m=9, G r=80$, and $\lambda=0.1$.

concentration sketches are prearranged in Figures 12-19. These figures indicate that the values of temperature and concentration disseminations and their boundary layer thickness decrease with increase of thermal and solutal jump parameters $s 2$ and $s 3$, nonlinear convection parameters $(\lambda$, $s)$, and thermal and solutal Grashof numbers $(\mathrm{Gr}, \mathrm{Gm})$. These effects happen due to the decline in the kinematic viscosity of the fluid which reduces thermal diffusion, that leads to a decrease in thermal and solutal boundary layer thicknesses. 


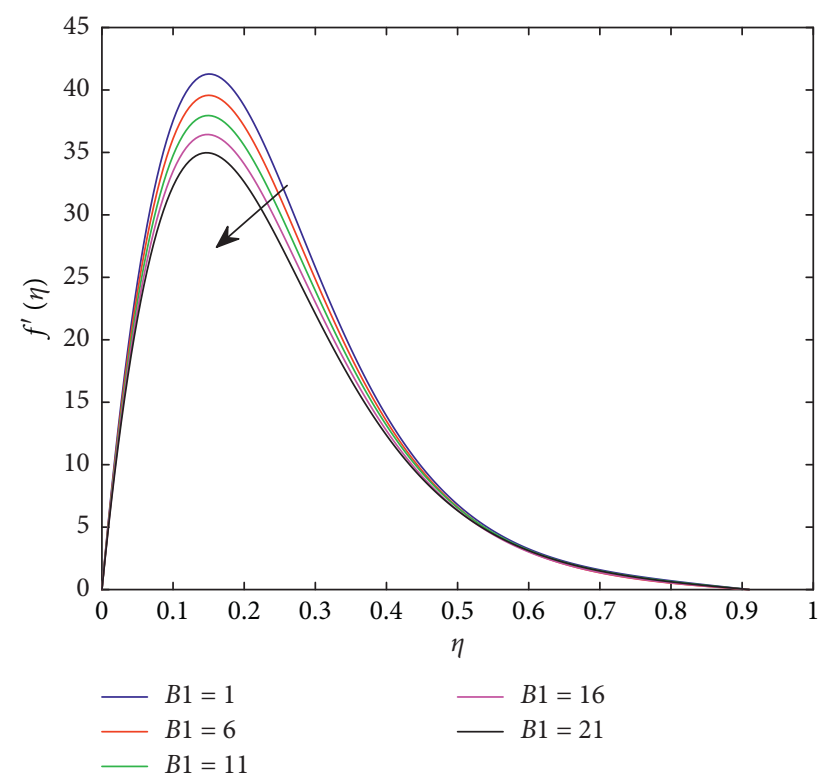

Figure 10: Graph $f^{\prime}$ profile for different values of $B 1$ when $G m=0.9$ and $G r=80$.

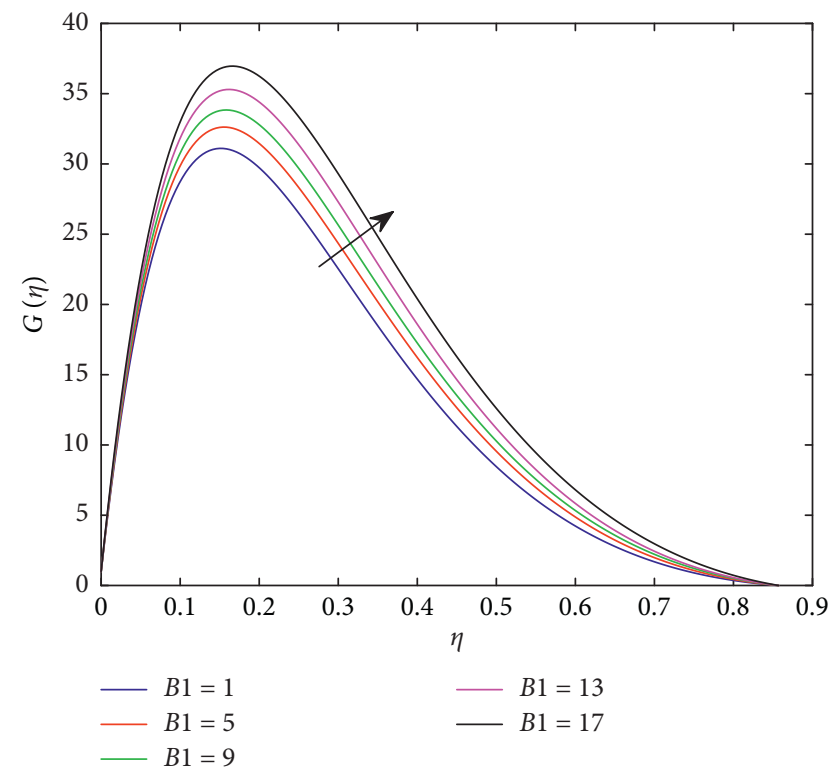

FIgURE 11: Graph $G(\eta)$ for different values of $B 1$ when $G m=9$ and $G r=80$.

4.3. Skin Frictions and Wall Couple Stresses. The impacts of thermal and solutal nonlinear convection parameters $(\lambda$, s), thermal and solutal Grashof numbers $(G r, G m)$, angular velocity parameters $(B 1-B 5)$ on skin friction coefficients $\left(f^{\prime \prime}(0), G^{\prime}(0)\right)$, and wall duos coefficients $\left(H^{\prime} 1(0)\right.$, $\left.-H^{\prime} 2(0),-H^{\prime} 3(0)\right)$ sketches are prearranged in Figures 20-35. Table 1 and Figures 20 and 29 illustrate that

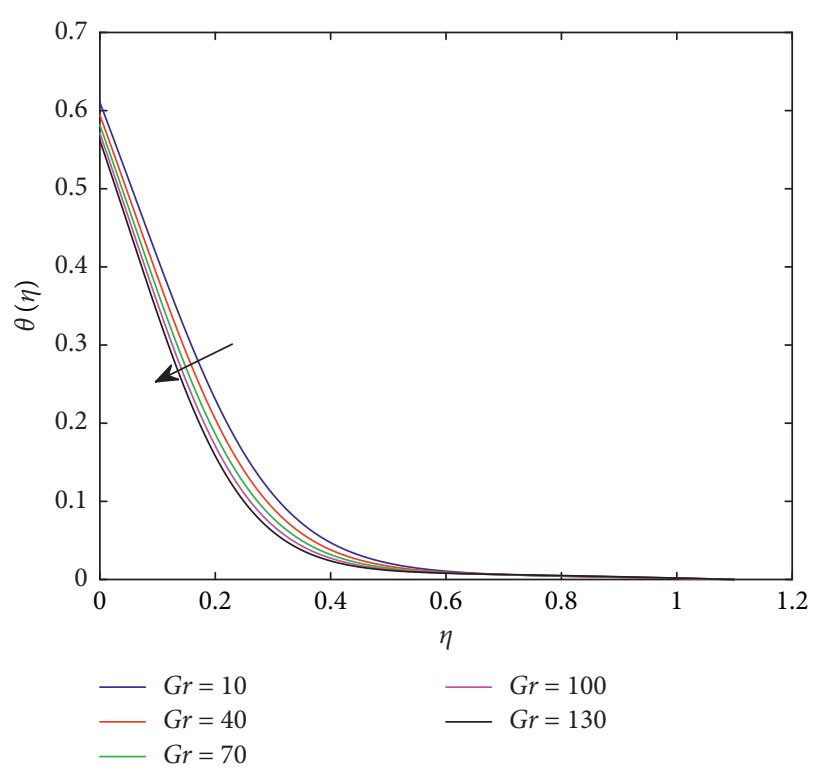

Figure 12: Graph $\theta(\eta)$ profile for different values of $G r$ when $G m=80, \quad B 2=B 5=s 2=0.2, \quad s 0=0, \quad B 6=3, \quad B 3=s 1=s=$ $N b=0.1, B 4=5, s 3=L e==N t=\lambda=0.5, R e=0.01, \operatorname{Pr}=0.72$, and $B 1=\omega=1$.

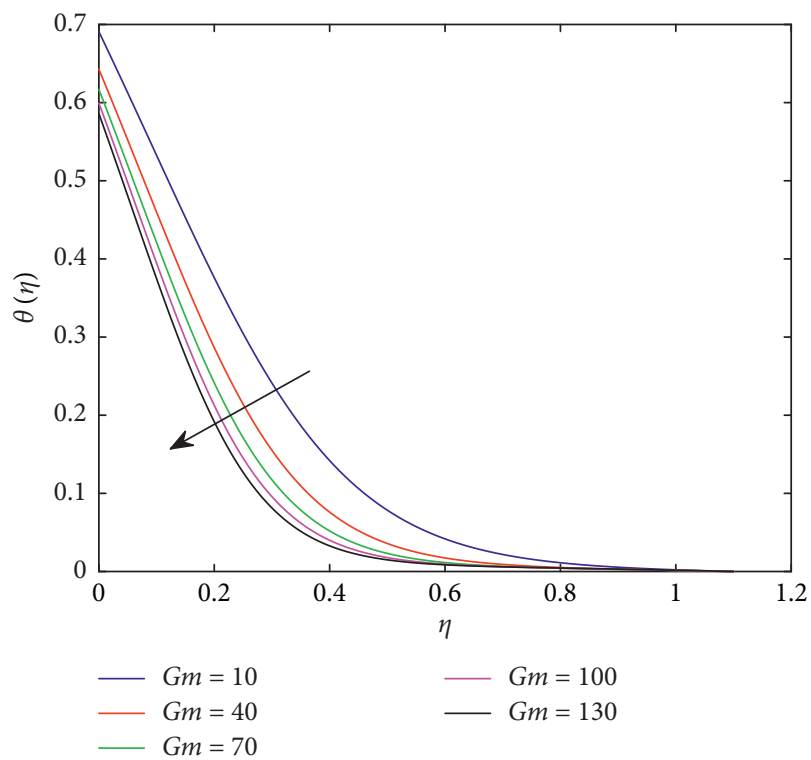

Figure 13: Graph $\theta(\eta)$ for different values of $G m$ when $G r=10$.

upsurge in values of $B 1$ reduces the kinematic viscosity of the fluid flow which falls opposite to the flow of the fluid that results in decline of the skin friction coefficients $f^{\prime \prime}(0)$ and wall duos coefficients $-H_{2}^{\prime}(0)$; Table 1 demonstrates that increase in velocity slip parameter $s 0$ reduces skin friction coefficients $f^{\prime \prime}(0), G^{\prime}(0)$, whereas the 


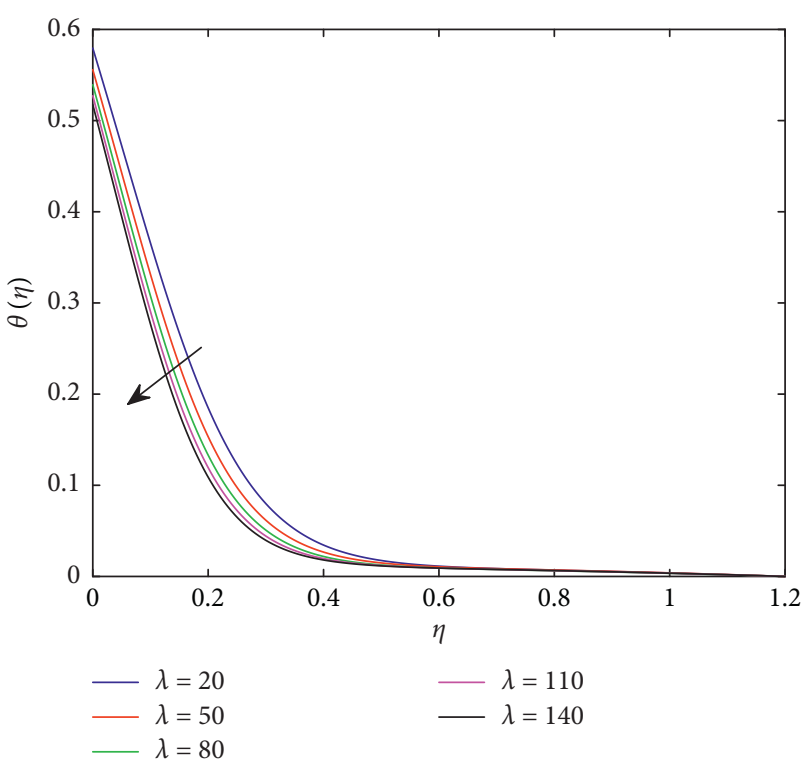

FIGURE 14: Graph $\theta(\eta)$ profile for different values of $\lambda$ when $s=0.5$.

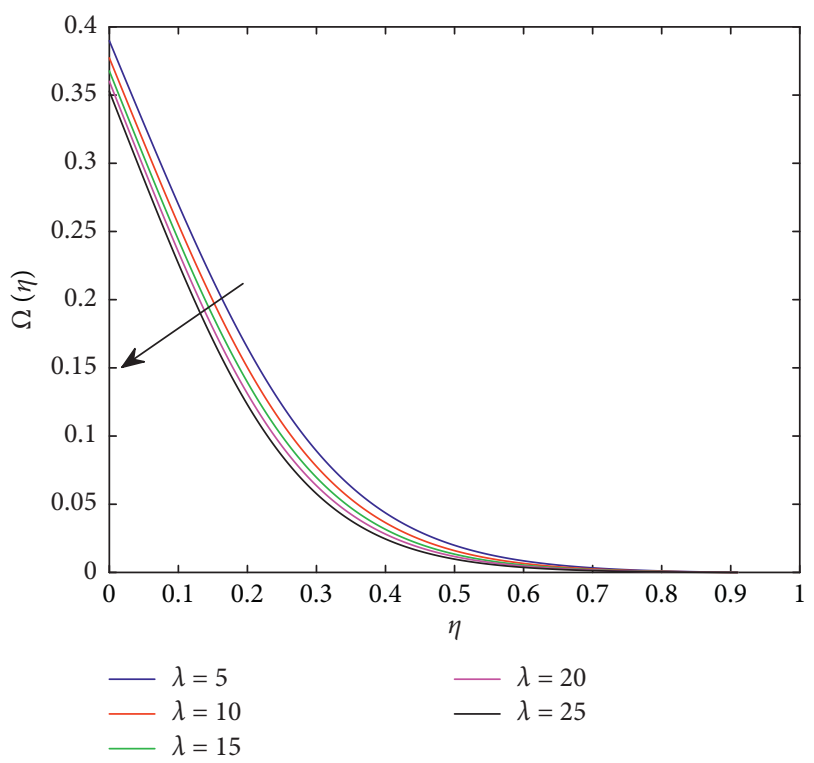

Figure 15: Graph $\Omega(\eta)$ for different values of $\lambda$ when $G r=20$.

opposite effects are observed on the skin friction coefficients $G^{\prime}(0)$ and wall duos coefficients $H_{1}^{\prime}(0)$. Moreover, Figures 22-27 show that boost in values of $\lambda, s, G r$, and $G m$ raise density of the fluid flow which increases resistance to the flow of the result upsurge skin friction coefficients $f^{\prime \prime}(0)$ and $G^{\prime}(0)$. Similarly, Figures 30 and 31 indicate that an increase in values of $B 2$ improves vortex viscosity of the fluid flow which enlarges resistance to rotate the fluid that results in upsurge wall duos coefficients $H_{1}^{\prime}(0)$ and $-H_{2}^{\prime}(0)$. Furthermore, increase in values of $B 3$, improve wall couple coefficients $-H_{2}^{\prime}(0)$ but bring down wall couple

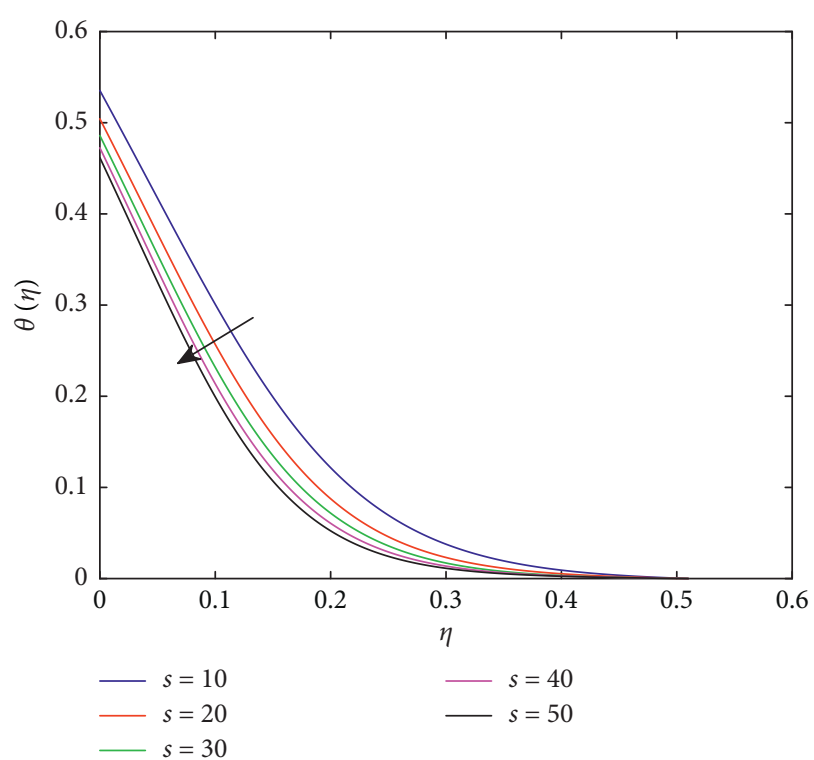

Figure 16: Graph $\theta(\eta)$ profile for different values of $s$ when $G r=1$ and $\lambda=0.5$.

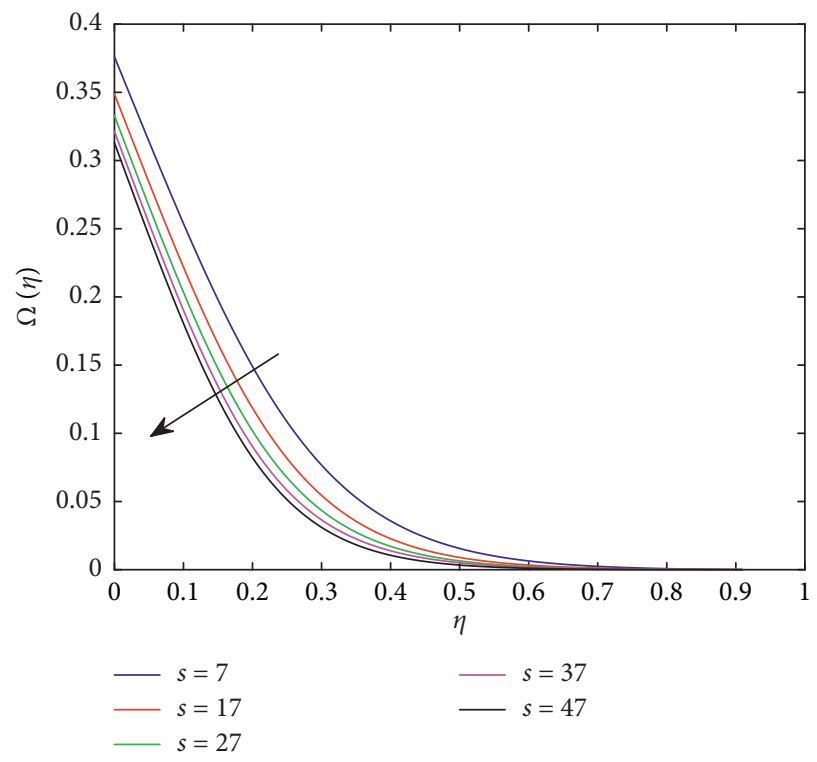

FIgURE 17: Graph $\Omega(\eta)$ for different values of $s$ when $N b=0.5$ and $N t=\lambda=0.1$.

coefficients $H_{1}^{\prime}(0)$ as indicated in Figures 32 and 33. Next, wall couple coefficients $-H_{2}^{\prime}(0)$ reduces with raise values of $B 4$ and $B 5$ in the boundary layer, as shown in Figures 34 and 35 .

4.4. Nusselt and Sherwood Numbers. The impacts of Prandtl Pr, Lewis Le numbers, thermal, solutal $(s 2, s 3)$, and Brownian motion $N b$ parameters on Nusselt $-\theta^{\prime}(0)$, and Sherwood numbers $\Omega^{\prime}(0)$ are presented in Figures 36-41. Figure 36 illustrates that boost in values of Pr bring down thermal diffusion of the temperature that cause upsurge Nusselt number $-\theta^{\prime}(0)$ near the surface of the disk. 


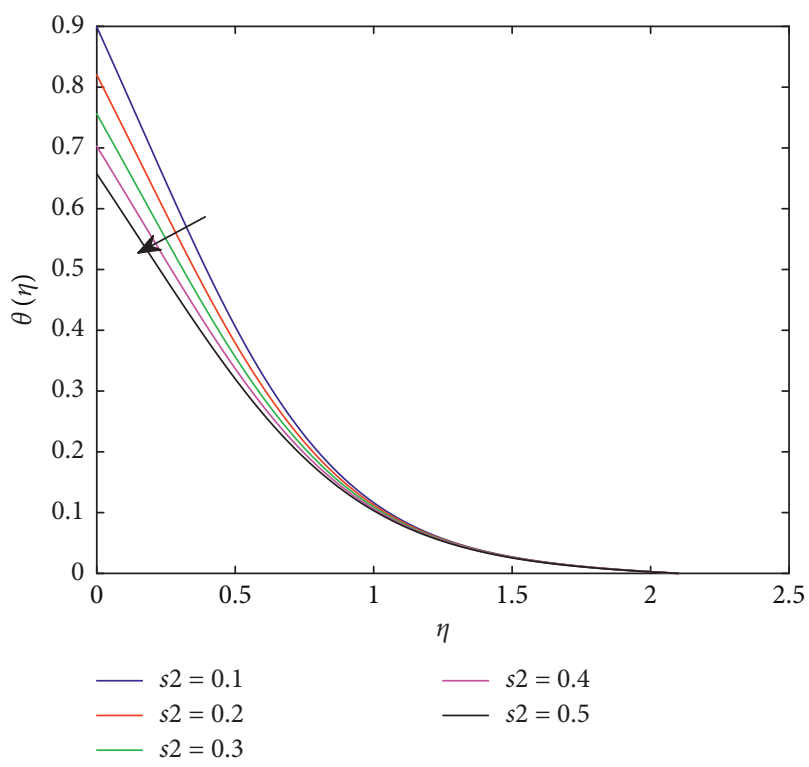

Figure 18: Graph $\theta(\eta)$ profile for different values of $s 2$ when $G m=0.1$.

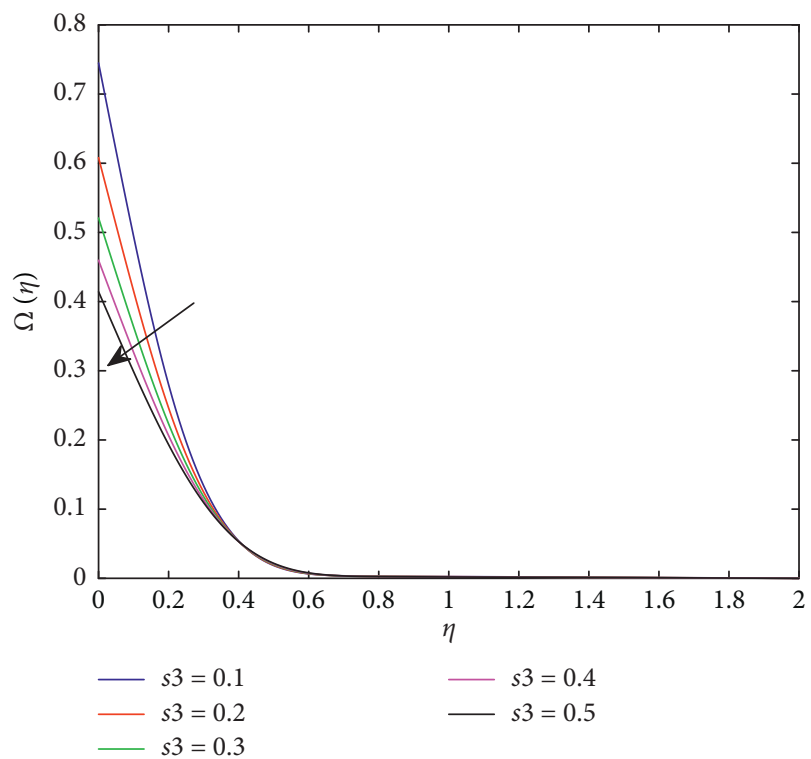

FIgURE 19: Graph $\Omega(\eta)$ for different values of $s 3$ when $G r=1$.

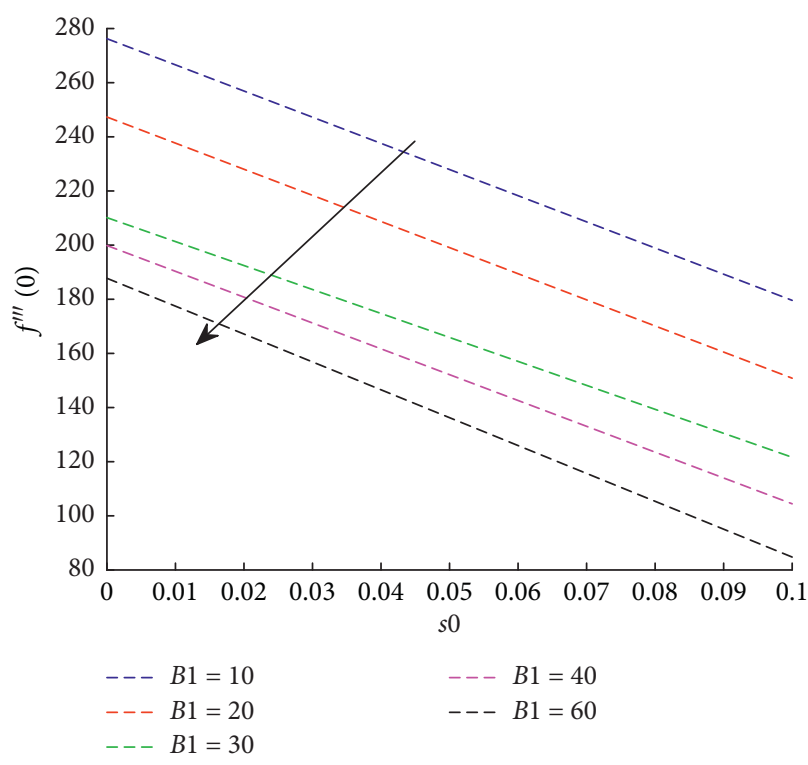

Figure 20: Graph $f^{\prime \prime}(0)$ profile for different values of $B 1$ when $G m=G r=10, \quad B 2=B 3=B 4=s=0.5, \quad s 0=0, \quad B 6=s 2=0.2$, $B 5=s 3=\lambda=0.1, \quad N b=0.5 . s 3=L e=0.7, \quad N t=2, \quad R e=0.01$, $\operatorname{Pr}=0.6$, and $\omega=1$.

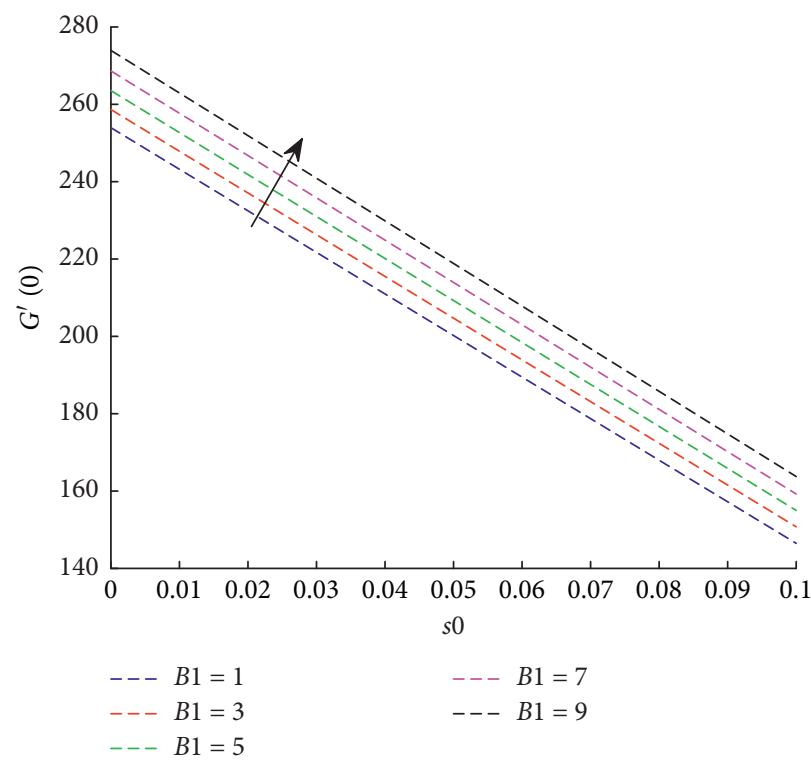

Figure 21: Graph $G^{\prime}(0)$ for different values of $B 1$. 


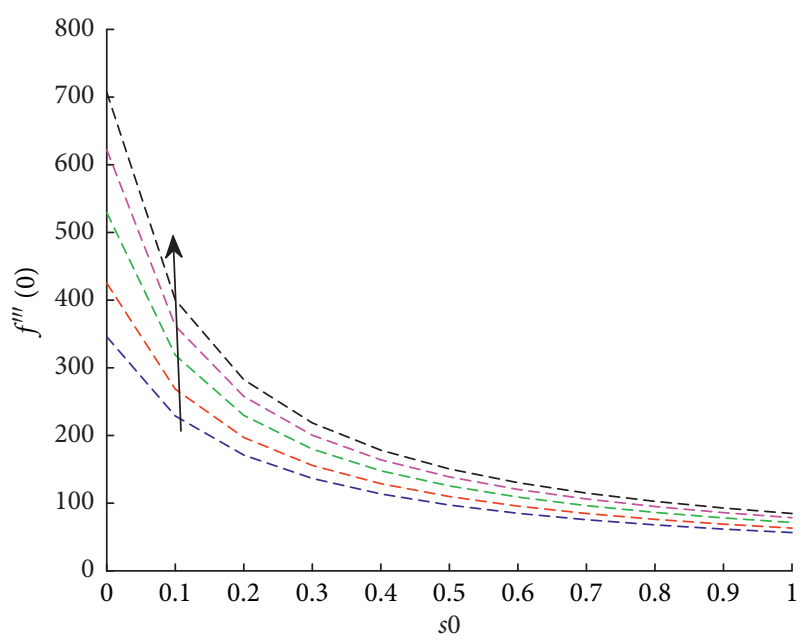
-- $\lambda=1$
$--\lambda=3$
$--\lambda=6$

Figure 22: Graph $f^{\prime \prime}(0)$ profile for different values of $\lambda$.

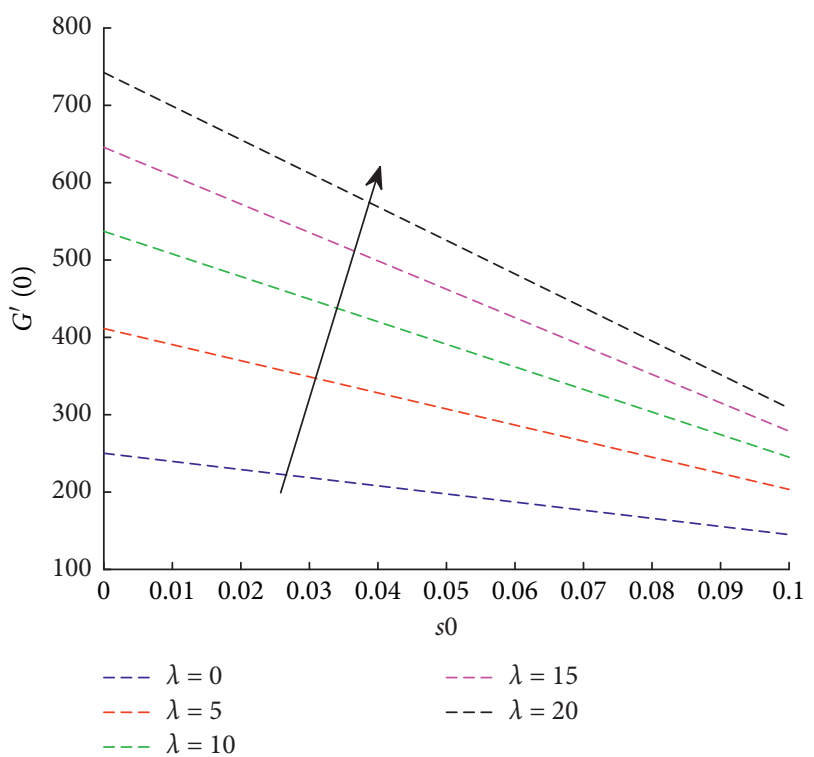

Figure 23: Graph $G^{\prime}(0)$ for different values of $\lambda$.

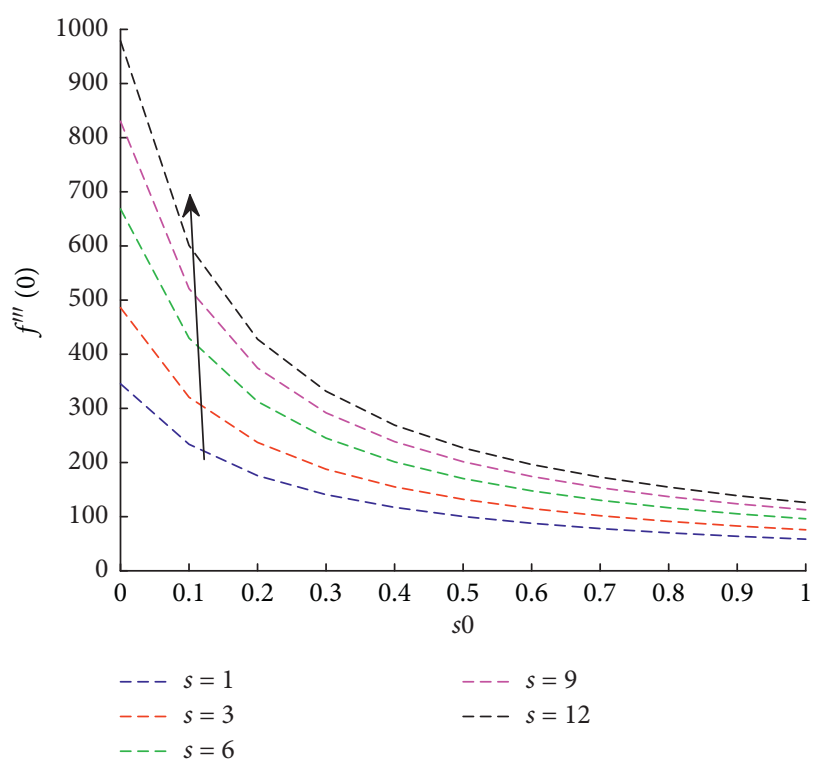

Figure 24: Graph $f^{\prime \prime}(0)$ profile for different values of $s$.

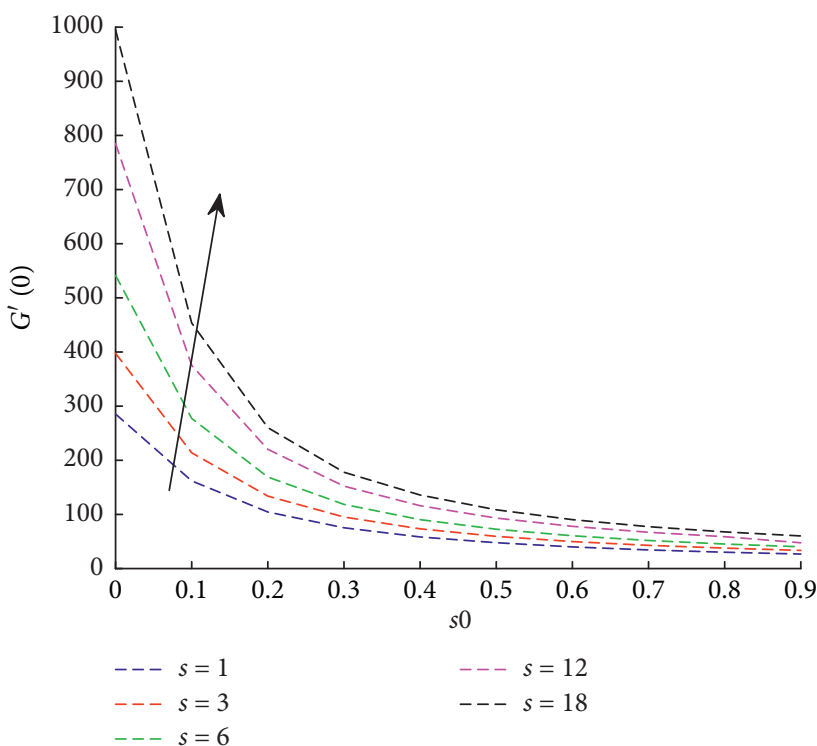

Figure 25: Graph $G^{\prime}(0)$ for different values of $s$. 


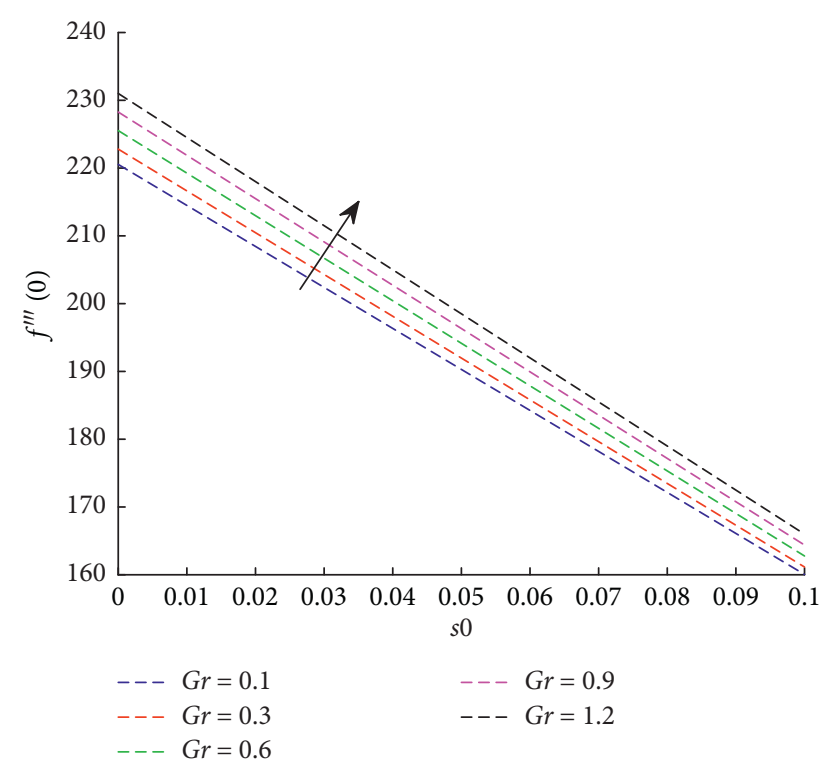

Figure 26: Graph $f^{\prime \prime}(0)$ profile for different values of $G r$.

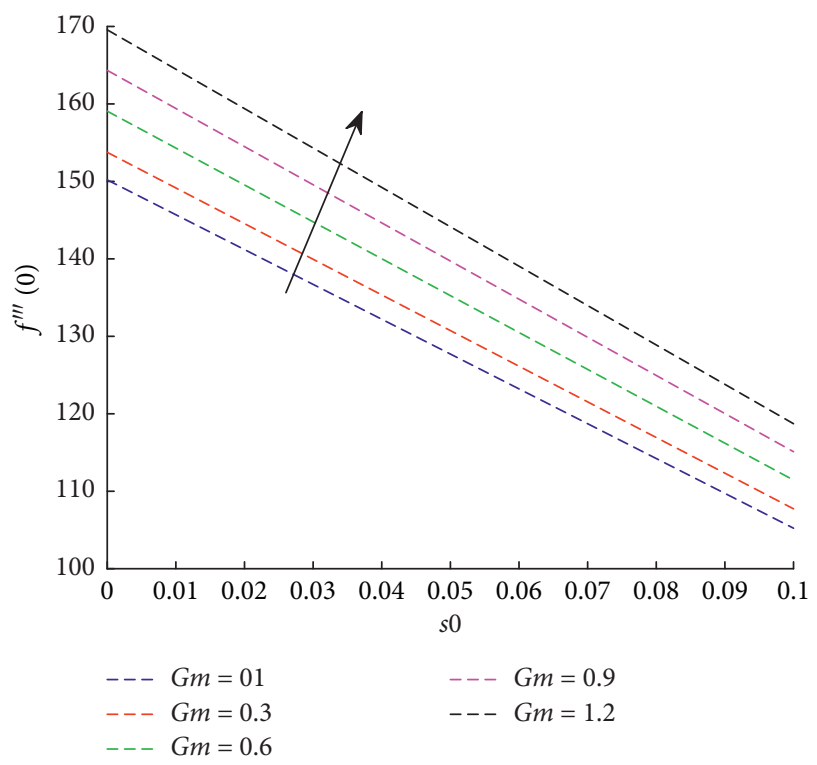

Figure 27: Graph $f^{\prime \prime}(0)$ for different values of $G m$.

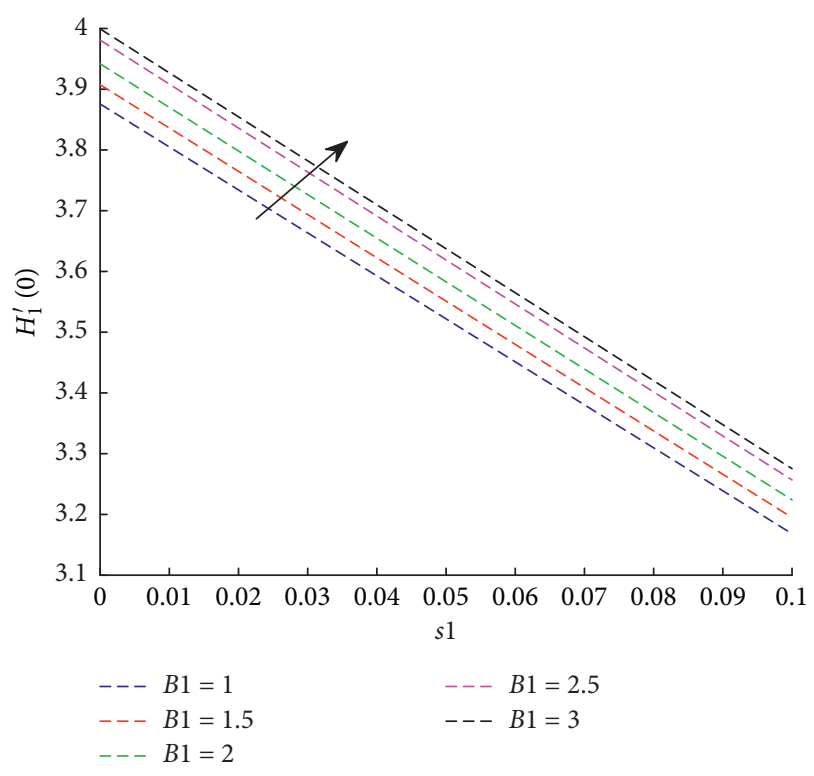

FIgURE 28: Graph $H_{1}^{\prime}(0)$ profile for different values of $B 1$ when $G m=G r=10, \quad B 2=B 3=B 4=s=0.5, \quad s 0=0, \quad B 6=s 2=0.2$, $B 5=s 3=\lambda=0.1, \quad N b=0.5 . s 3=L e=0.7, \quad N t=2, \quad R e=0.01$, $\operatorname{Pr}=0.6$, and $\omega=1$.

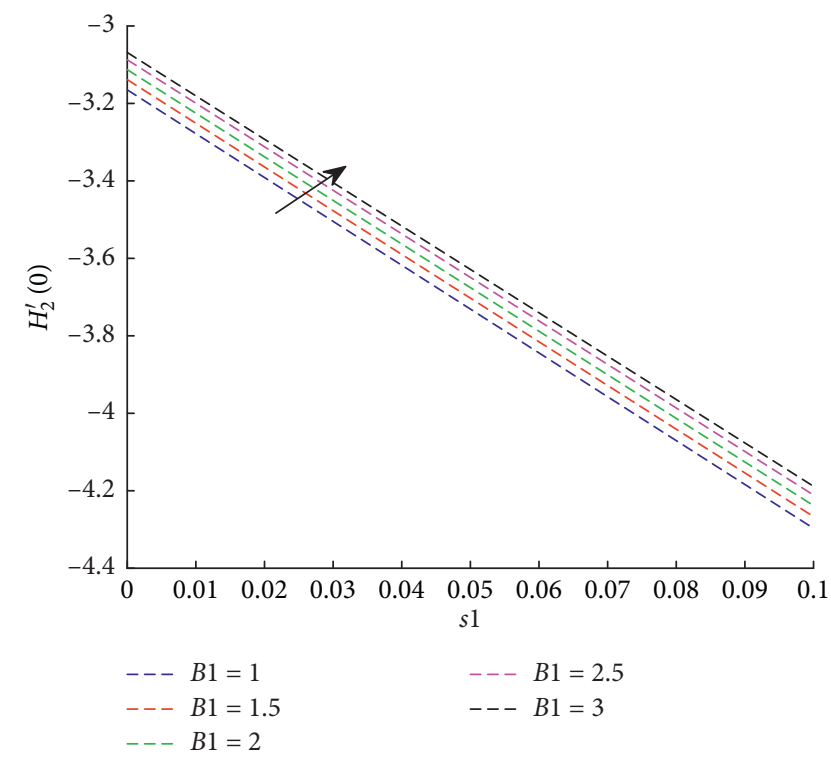

Figure 29: Graph $-H_{2}^{\prime}(0)$ for different values of $B 1$. 


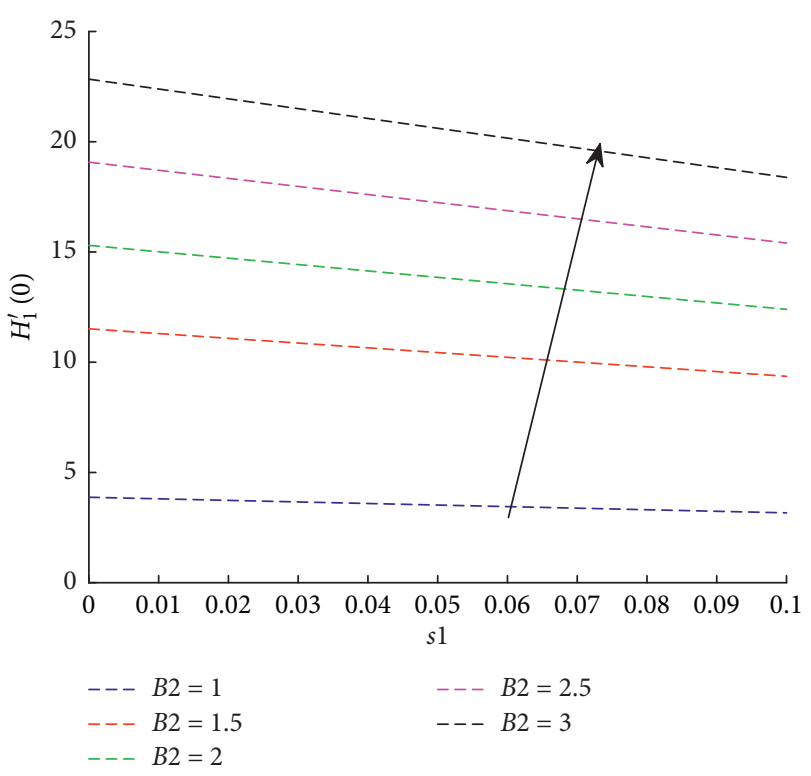

Figure 30: Graph $H_{1}^{\prime}(0)$ profile for different values of $B 2$.

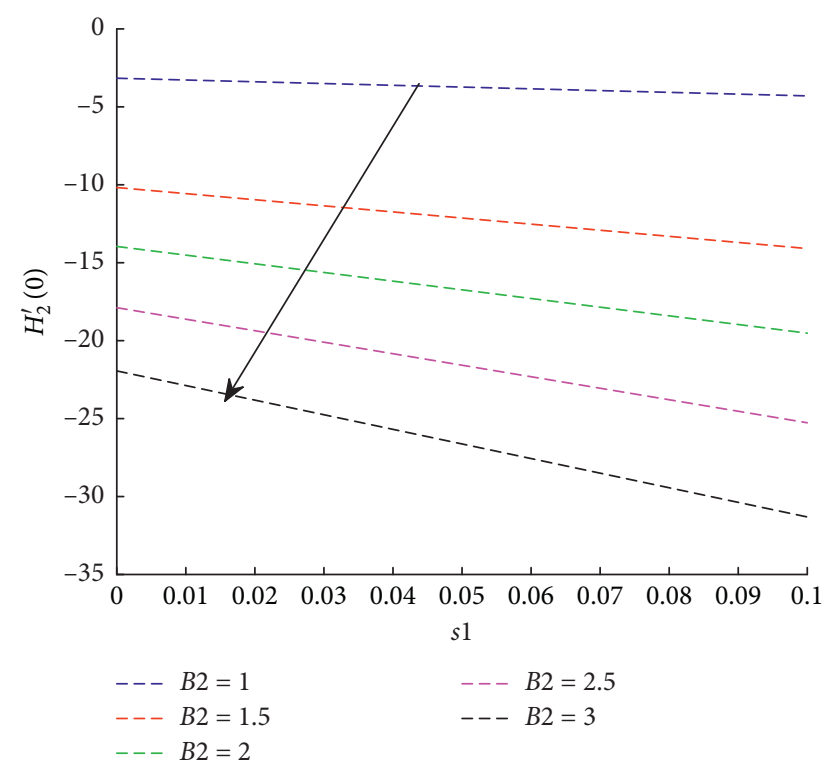

FIgURE 31: Graph $-H_{2}^{\prime}(0)$ for different values of $B 2$.

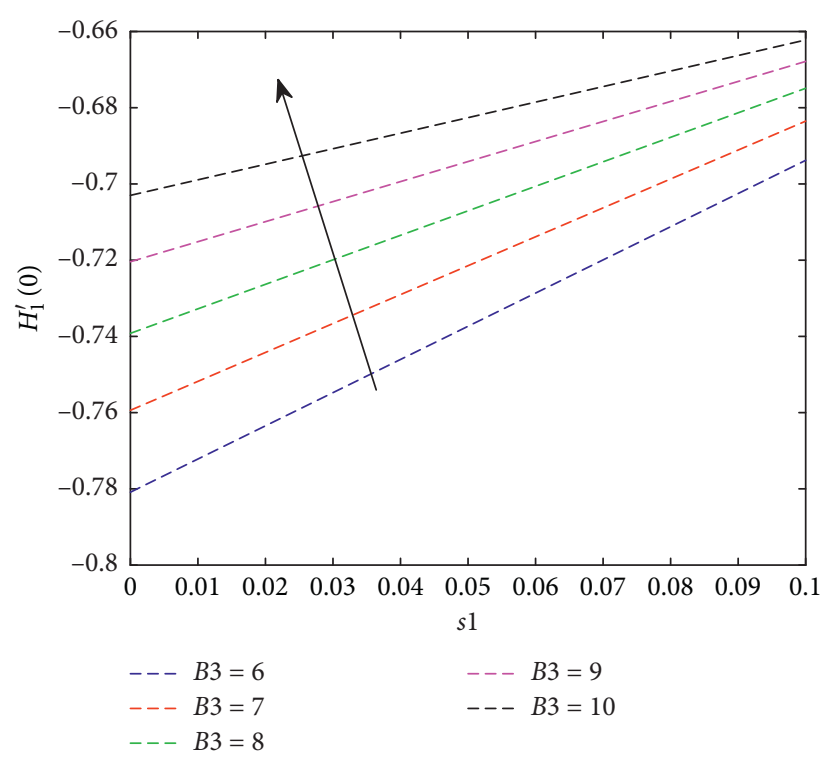

Figure 32: Graph $H_{1}^{\prime}(0)$ profile for different values of $B 3$ when $G r=G m=1$.

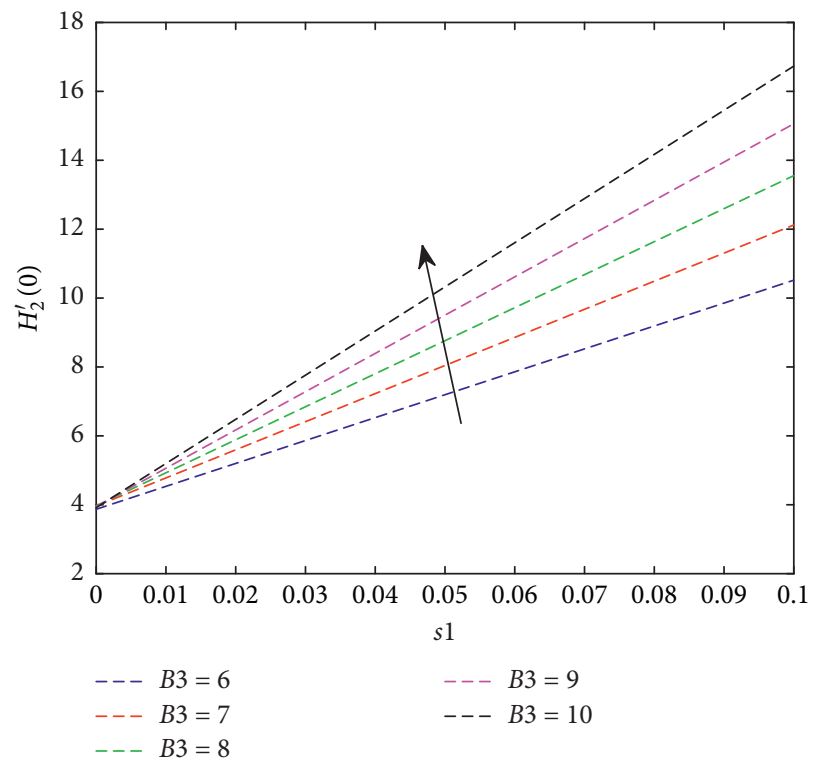

Figure 33: Graph $-H_{2}^{\prime}(0)$ for different values of $B 3$ when $G r=1$ and $G m=12$. 


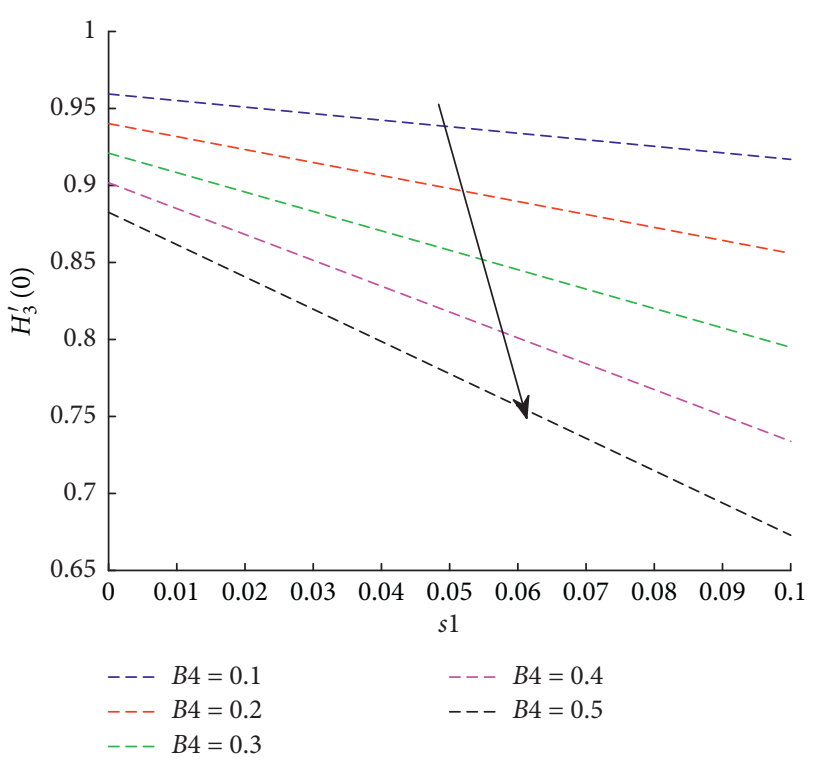

Figure 34: Graph $-H_{3}^{\prime}(0)$ profile for different values of $B 4$.

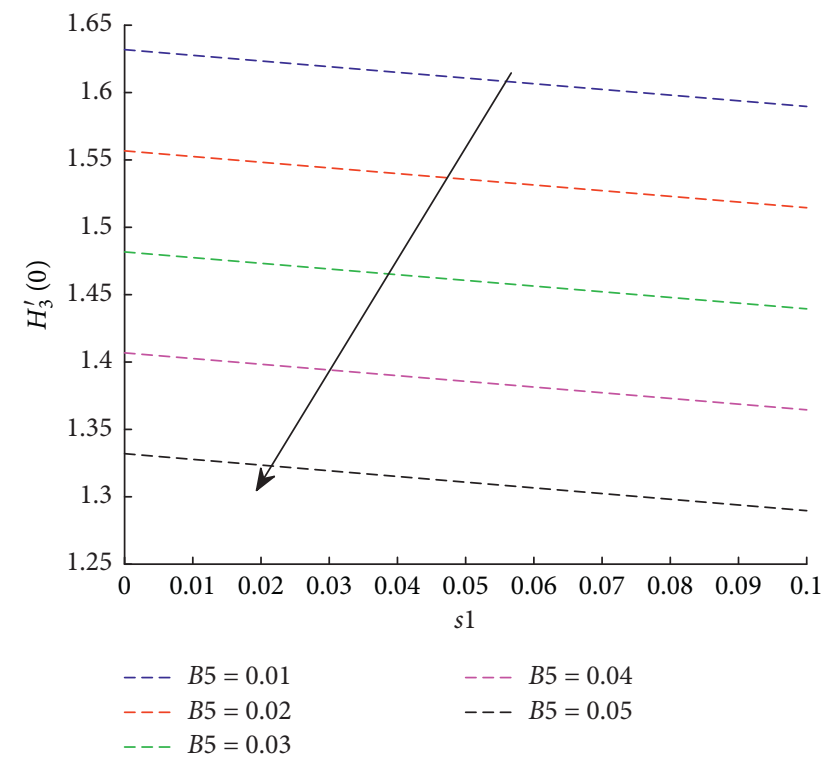

FIgURE 35: Graph $-H_{3}^{\prime}(0)$ for different values of $B 5$.

TABle 1: The computed values of skin friction coefficients $f^{\prime \prime}(0)$ and $G^{\prime}(0)$, when $B 3=0.2, \quad B 4=B 5=G r=G m=s 2=s=$ $\lambda=N t=0.1, B 6=0.3, R e=0.01, N b=L e=s 3=0.5, \operatorname{Pr}=0.72$, and $\omega=1$.

\begin{tabular}{lcccc}
\hline$B 1$ & $B 2$ & $s 0$ & $f^{\prime \prime}(0)$ & $G^{\prime}(0)$ \\
\hline 0.1 & 0.1 & 0.1 & 0.8116 & 0.7618 \\
0.2 & 0.1 & 0.1 & 0.8104 & 0.7624 \\
0.3 & 0.1 & 0.1 & 0.8093 & 0.7631 \\
0.1 & 3 & 0.1 & & 0.7642 \\
0.1 & 5 & 0.1 & & 0.7656 \\
0.1 & 7 & 0.1 & & 0.7668 \\
0.1 & 0.1 & 0.3 & 0.2571 & 0.5304 \\
0.1 & 0.1 & 0.4 & 0.2152 & 0.4571 \\
0.1 & 0.1 & 0.5 & 0.1850 & 0.4002 \\
\hline
\end{tabular}

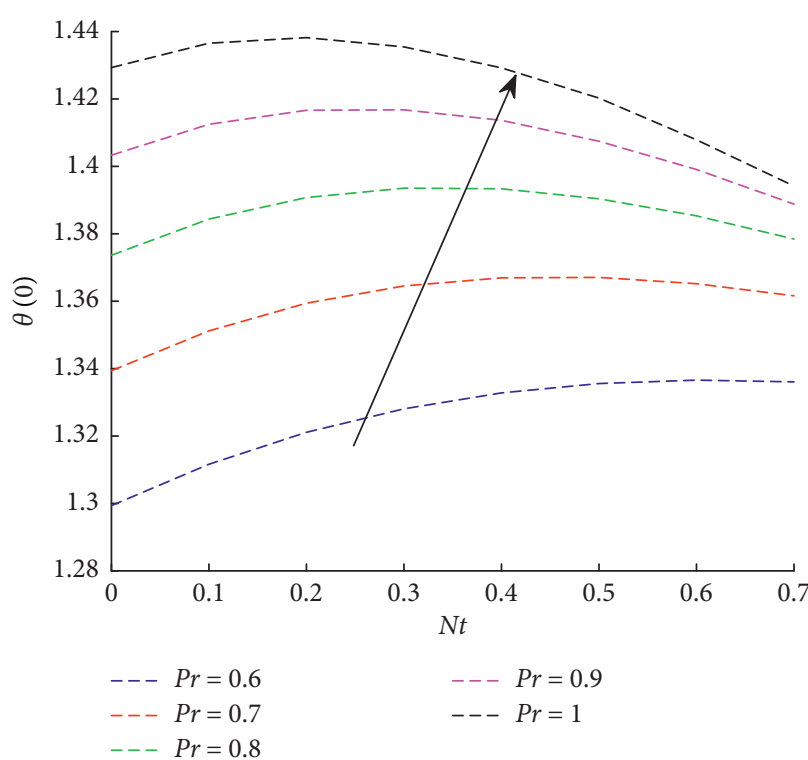

Figure 36: Graph $-\theta^{\prime}(0)$ profile for different values of Pr when $G m=10, G r=B 2=B 3=5, s 0=0, B 6=0.2, B 5=s 2=\lambda=G r=$ $0.1, \quad N b=B 4=s=s 3=L e=0.5, \quad N t=2, \quad R e=0.01, \quad$ and $B 1=\omega=1$.

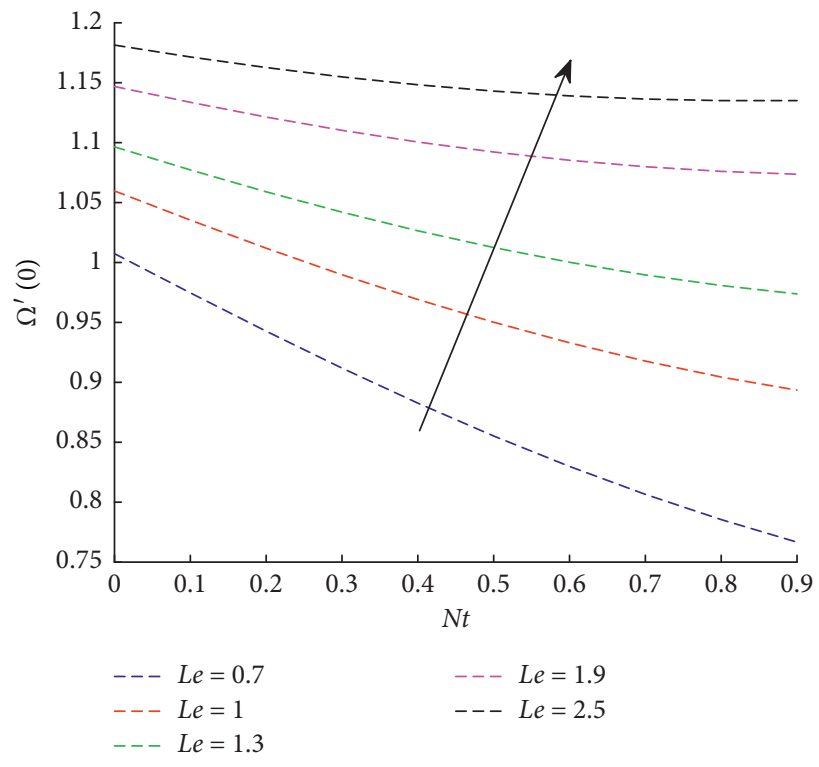

Figure 37: Graph $\Omega^{\prime}(0)$ for different values of $L e$.

Figure 37 demonstrates that a rise in the values of Le reduces the density of the fluid, as a result the Sherwood number $\Omega^{\prime}(0)$ increased, whereas an increment in the values $s 2$ and $s 3$ reduces the Nusselt number $-\theta^{\prime}(0)$ and Sherwood number $\Omega^{\prime}(0)$ as demonstrated in Figures 3839. Figures 40 and 41 show the impact of Brownian motion parameter $\mathrm{Nb}$ on Nusselt number $-\theta^{\prime}(0)$ and Sherwood number $\Omega^{\prime}(0)$. From the figures, it is possible to see that $\mathrm{Nb}$ favors the Nusselt number and opposite effect on the Sherwood number. 


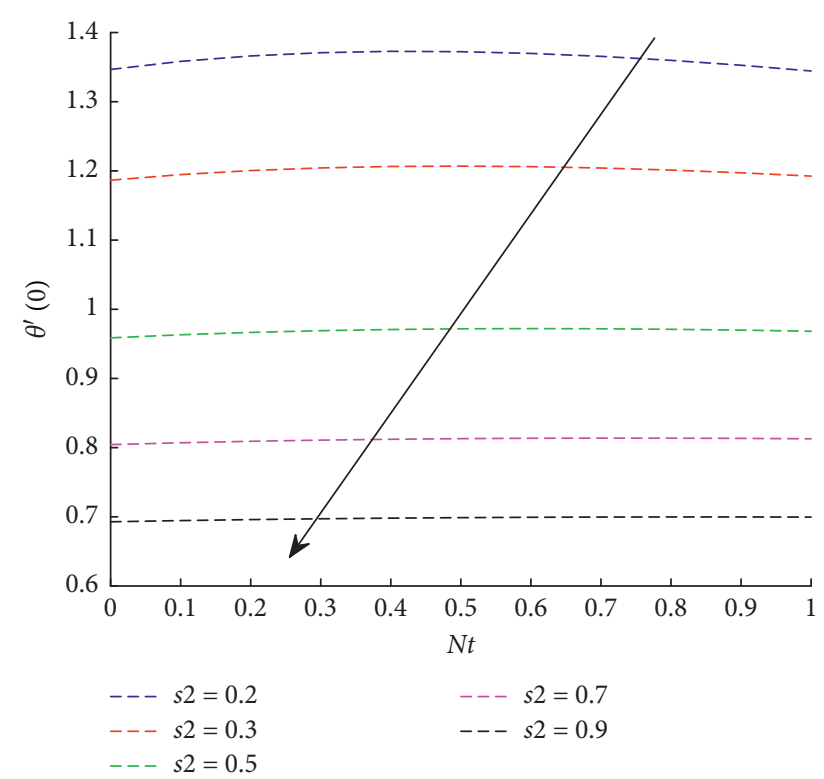

Figure 38: Graph $-\theta^{\prime}(0)$ profile for different values of $s 2$.

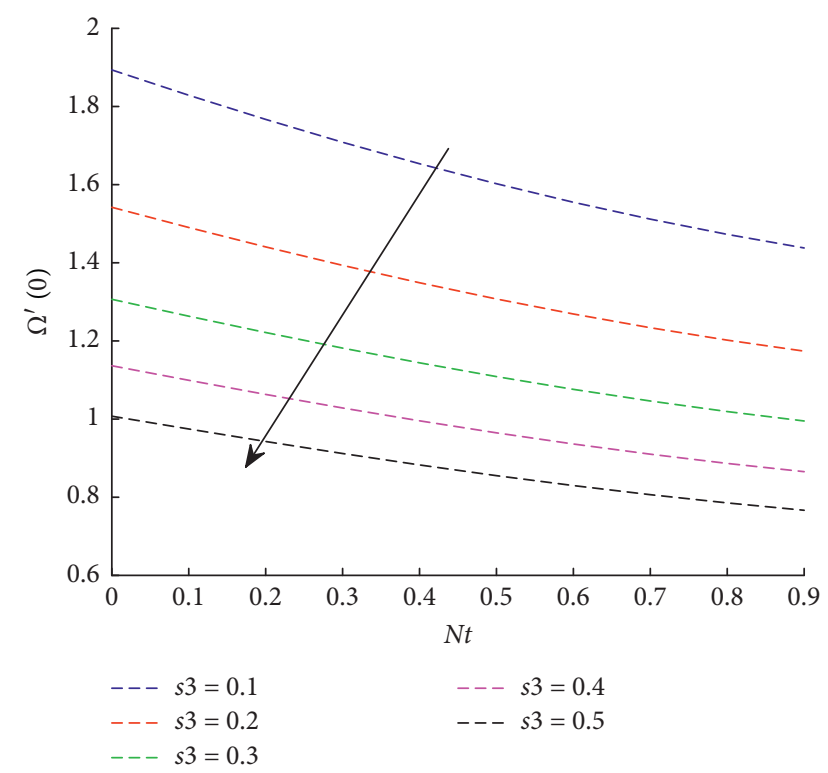

Figure 39: Graph $\Omega^{\prime}(0)$ for different values of $s 3$.

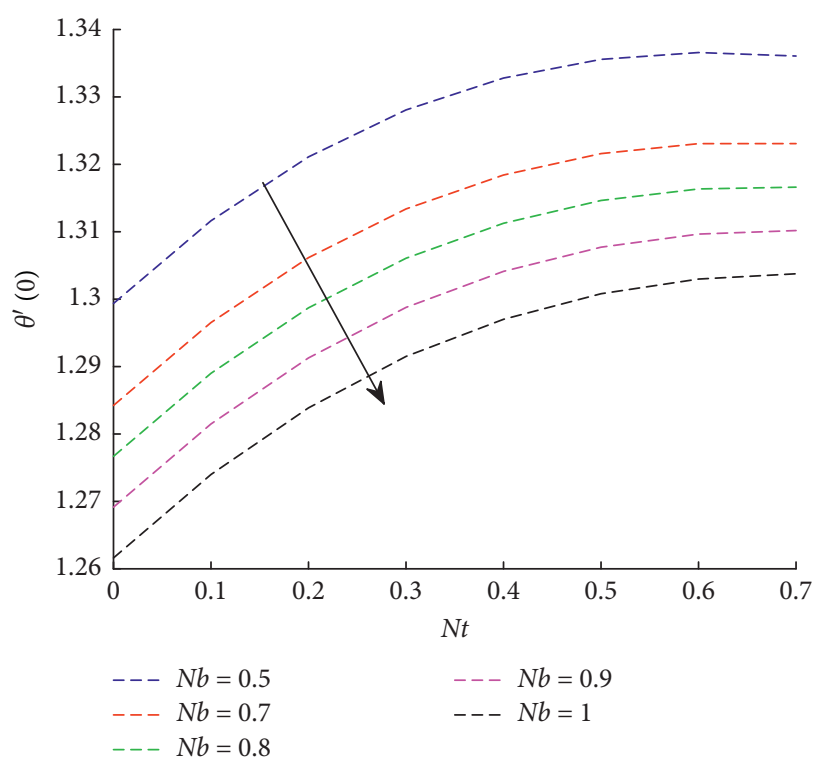

Figure 40: Graph $-\theta^{\prime}(0)$ profile for different values of $N b$.

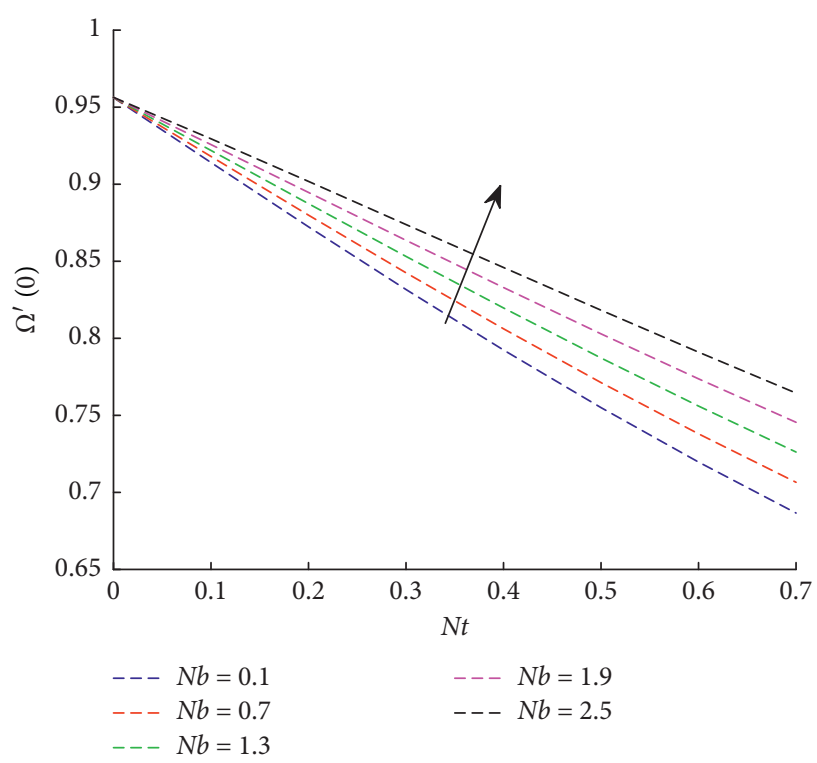

FIgURE 41: Graph $\Omega^{\prime}(0)$ for different values of $N b$. 


\section{Conclusions}

This report considers the effects of thermal and solutal nonlinear convection as well as manifold slip conditions on dimensional boundary layer flow of a micropolar nanofluid due to a rotating disk were analysed. The boundary layer equations of the flow problem are reduced into a pairs of high-order nonlinear ordinary differential equations by using the similarity transformation. The obtained differential equations are solved numerically using bvp $4 \mathrm{c}$ from matlab software. Numerical outcomes are acquired for different main parameters of the flow problem. The effects of governing parameters are presented by means of figures and tables. The main findings are

(1) An increasing in the values of thermal and solutal nonlinear convection parameters allow to increase in the value of velocities $f^{\prime}(\eta)$ and $G(\eta)$ near surface of the disk and reduce at far from the disk as well as thermal and solutal Grashof numbers tolerate to increase the value of radial velocity $f^{\prime}(\eta)$ near surface of the disk.

(2) Velocity profile $G(\eta)$ is positive throughout its boundary, indicating in that way there is outward flow from the disk which reaches the particular point and it drops to zero when far from the surface of the disk.

(3) The existence of the thermal and solutal jump, nonlinear convection parameters, and Grashof numbers allows to decline the temperature and concentration distributions near the disk surface.

(4) Radial skin friction coefficients exhibit increasing behavior for increasing thermal and solutal nonlinear convection parameters and Grashof numbers; skin friction coefficients $G^{\prime}(0)$ exhibit increasing behavior for increasing thermal and solutal nonlinear convection parameters.

(5) An increase in quantities of $\mathrm{Pr}$ and Le causes enhancement in the Nusselt and Sherwood numbers while they fall as magnitudes of $s 2$ and $s 3$ increase, accordingly.

(6) The value of wall couple coefficients $\left(H_{1}^{\prime}(0),-H_{2}^{\prime}(0)\right)$ increase with $B 2$. However, they rotate in opposite directions.

(7) An improvement in the values of angular velocity parameters $(B 1, B 3)$ allows to rotate the wall couple stresses $\left(H_{1}^{\prime}(0)\right.$ and $\left.H_{2}^{\prime}(0)\right)$ in opposite directions.

\section{Nomenclature}

$\begin{array}{ll}a, b, c: & \text { Material constants (viscosity) } \\ C_{f r}, C_{f \omega}: & \text { Skin friction coefficients } \\ c_{p}: & \text { Specific heat }\left(\mathrm{Jkg}^{-1} \mathrm{~K}^{-1}\right) \\ (B 1-B 6): & \text { Microrotation parameters } \\ C: & \text { Concentration } \\ C_{\infty}: & \text { Ambient concentration }\end{array}$

\begin{tabular}{|c|c|c|}
\hline$C_{w}:$ & & Wall concentration \\
\hline$d:$ & & Radius of disk (m) \\
\hline$D_{T}:$ & & Thermophoretic diffusion \\
\hline$(f, G):$ & & Dimensionless functions \\
\hline$G r:$ & & Thermal Grashof number \\
\hline Gm: & & Solutal Grashof number \\
\hline$H 1, H 2$ & 2, H3: & Nondimension angular velocity \\
\hline$j:$ & & Microinertia density \\
\hline$h:$ & & Thermal jump factor $\left(\mathrm{m}^{-1}\right)$ \\
\hline$K:$ & & Thermal conductivity $\left(\mathrm{Wm}^{-1} \mathrm{~K}^{-1}\right)$ \\
\hline$m_{r}, m_{\omega}$ & & Wall couple stresses \\
\hline$L:$ & & Momentum slip factor $\left(\mathrm{m}^{-1}\right)$ \\
\hline$m:$ & & Solutal jump factor $\left(\mathrm{m}^{-1}\right)$ \\
\hline Le: & & Lewis number \\
\hline$M_{0}:$ & & Solutal jump factor $\left(\mathrm{m}^{-1}\right)$ \\
\hline$n:$ & & Angular slip factor $\left(\mathrm{m}^{-1}\right)$ \\
\hline$N_{1}, N_{2}$ & $, N_{3}:$ & Angular components \\
\hline$N b:$ & & Brownian motion parameter \\
\hline$N t:$ & & Thermophoresis parameter \\
\hline Nu: & & Local Nusselt number \\
\hline Pr: & & Prandtl number \\
\hline$q_{w}, q_{m}:$ & & Heat and mass fluxes $\left(\mathrm{Wm}^{-2},\left(\mathrm{Kg} / \mathrm{m}^{2} \mathrm{~s}\right)\right)$ \\
\hline$(r, \omega, z$ & & Polar coordinates \\
\hline Re: & & Reynolds number \\
\hline Sh: & & Sherwood number \\
\hline s3: & & Solutal jump parameter \\
\hline$s:$ & & Solutal nonlinear convection parameter \\
\hline s2: & & Thermal jump parameter \\
\hline$s 0$ : & & Velocity slip parameters \\
\hline$s 1:$ & & Microrotation slip parameters \\
\hline$T_{w}:$ & & Wall temperature $(\mathrm{K})$ \\
\hline$T_{\infty}:$ & & Ambient temperature $(\mathrm{K})$ \\
\hline$(u, v, u$ & & Velocity components $\left(\mathrm{ms}^{-1}\right)$ \\
\hline$T:$ & & Temperature of the fluid $(\mathrm{K})$ \\
\hline Greeks & & \\
\hline$\lambda:$ & Thern & nal nonlinear convection parameter \\
\hline$\sigma_{t}, \sigma_{s}:$ & Thern & nal and volumetric expansion \\
\hline$\sigma, \sigma^{*}:$ & Const & ants \\
\hline$\eta:$ & Dime & nsionless similarity variable \\
\hline$\theta:$ & Dime & nsionless temperature \\
\hline$\Omega:$ & Dime & nsionless concentration \\
\hline$\omega:$ & Dime & nsionless stream wise coordinate \\
\hline$\mu:$ & Fluid & viscosity $(\mathrm{Pa} \cdot \mathrm{s})$ \\
\hline$\kappa:$ & Vorte & $\mathrm{x}$ viscosity coefficient $(\mathrm{Pa} \cdot \mathrm{s})$ \\
\hline$\nu:$ & Kinen & natic viscosity coeff. $\left(\mathrm{m}^{2} \mathrm{~s}^{-1}\right)$ \\
\hline$\rho:$ & Fluid & density $\left(\mathrm{Kg} \cdot \mathrm{m}^{-3}\right)$ \\
\hline$\tau_{w}:$ & Wall & shear stress $(\mathrm{Pa})$ \\
\hline
\end{tabular}

\section{Data Availability}

The data used to support the findings of this study are available from the corresponding author upon request. 


\section{Conflicts of Interest}

The authors declare that they have no conflicts of interest.

\section{References}

[1] A. Eringen, "Theory of micropolar fluids," Indiana University Mathematics Journal, vol. 16, no. 1, pp. 1-18, 1966.

[2] T. A. Hamzeh, "Numerical solution of micro polar Casson fluid behaviour on seady MHD natural convective flow about a solid sphere," Journal of Advanced Reseach in Fluid Mechenic and Thermal Science, vol. 50, pp. 55-66, 2018.

[3] I. Wubshet and Z. Chaluma, "Non-linear convection flow of micropolar nanofluid past an isotermal sphere," Journal of Physics Communications, vol. 3, no. 11, Article ID 115017, 2019.

[4] I. C. Mandal and S. Mukhopadhyay, "Non-linear convection in micropolar fluid flow past an exponentially stretching sheet in an exponentially moving stream with thermal radiation," Mechanics of Advanced Material and Structures, vol. 26, no. 24, pp. 2040-2046, 2018.

[5] T. Mustafa, "MHD fluid flow and heat transfer due to a stretching rotating disk," International of Thermal Sciences, vol. 51, pp. 195-201, 2012.

[6] S. Akhter, M. Ashraf, and K. Ali, "MHD flow and heat transfer analysis of micropolar fluid through a porous medium between two stretchable disks using quasi- linearization method," Iranian Journal of Chemistry and Chemical Engineering, vol. 36, 2017.

[7] A. A. M. Mostafa and E. W. Shimaa, "MHD flow and heat transfer of amicropolar fluid over a stretching surface with heat generation (absorption) and slip velocity," Journal of the Egyption Mathematics Society, vol. 20, pp. 20-27, 2012.

[8] M. Anwar and G. S. Guram, "Numerical solution of a micropolar flow between a rotating and a stationary disc," Computers \& Mathematics with Applications, vol. 6, no. 2, pp. 235-245, 1980.

[9] M. M. Rashidi and N. Freideonimehr, "Effects of velocity slip and temperature jump on the entropy generation in MHD flow over aporous rotatinng disk," Journal of Mechanical Engineering, vol. 1, no. 3, 2012.

[10] N. A. Khan, S. Aziz, and S. Ullah, "Entropy generation on Mhd flow of Powell- Eyring fluid between radially stretching disk with diffusion-thermo and thermo-diffusion effects," Acta Mechanica et Automatica, vol. 11, no. 1, pp. 20-32, 2017.

[11] H. Tasawar, Q. Sumaira, I. Maria, and A. Ahmed, "Radiative flow due to stretchable rotating disk with variable thickness," Results in Physics, vol. 7, pp. 156-165, 2017.

[12] M. D. Shamshuddin, S. R. Mishra, O. A. Bég, and A. Kadir, "Numerical study of heat transfer and viscous flow in a dual ratating extendable disk system with a non -fourior heat flux model," Heat Transfer-Asia Research, vol. 48, no. 1, pp. 435-459, 2019.

[13] N. A. Lafiff, M. J. Uddin, and A. I. M. Ismail, "Stefan blowing effect on bioconvective flow of nano fluid over a solid rotating stretchable disk," Propulsion and Power Research, vol. 5, no. 4, pp. 267-278, 2016.

[14] C. Yin, L. Zheng, C. Zhang, and X. Zhang, "Flow and heat transfer of nanofluids over a rotating disk with uniform stretching rate in the radial direction," Propulsion and Power Research, vol. 6, no. 1, pp. 25-30, 2017.

[15] R. Muhammad and U. Naeem, "Partial slip effects in flow mhd micropolar nano fluid flow due to rotating disk," Result In Physics, vol. 7, pp. 3557-3566, 2017.
[16] N. F. M. Noor, R. U. Haq, S. Nadeem, and I. Hashim, "Mixed convection stagnation flow of a micropolar nanofluid along a vertically stretching surface with slip effects," Meccanica, vol. 50, no. 8, pp. 2007-2022, 2015.

[17] B. Narfifah, I. Anwer, and I. Pop, "Flow and heat transfer over A rotating porous disk in a nanofluid," Physica, vol. B406, pp. 1767-1772, 2011.

[18] A. Mushtaq and M. Mustafa, "Computations for nanofluid flow near a stretchable rotating disk with axial magnetic field and convective conditions," Results in Physics, vol. 7, pp. 3137-3144, 2017.

[19] S. Anwer, S. Zahir, I. Saeed et al., "Three-dimensional Casson nanofluid thin flim flow over an inclined rotating disk with the impact of heat generation/comsumption and thermalradiation," Coatings, vol. 9, no. 4, p. 248, 2019.

[20] H. Tasawar, R. Madira, I. Maria, and A. Ahmed, "Magnetohydrodynamic MHD flow of $\mathrm{Cu}$-water nanofluid due to a rotating disk with partial slip," AIP Advances, vol. 5, Article ID 067169, 2015.

[21] J. Ahmad, M. H. M. Turkyilmazoglu, and A. Alsaedi, "Numerical study of nano fluid flow and heat transfer over a rotating disk using Buongiomo's model," Internal Journal of Numerical Methods for Heat and Fluid Flow, vol. 27, no. 1, pp. 221-234, 2017.

[22] C. Sumalatha and B. Shanker, "MHD mixed convection flow of a nanofluid over a nonlinear stretching sheet with variable brownian and thermophoretic diffusion coefficient," Physical Science International Journal, vol. 12, no. 1, pp. 1-10, 2016.

[23] H. Sajjad, K. M. Awar, and M. Shafique, "Similar flow of micropolar fluids between two discs in the presence of a magnetic field," Science of International, vol. 2, no. 3, pp. 57-63, 2012.

[24] L. F. Shampine, I. Gladwell, and S. Thomson, Solving ODEs with Matlab, Cambridge University Press, New York, NY, USA, 2003. 